\title{
The role of diversity and tolerance in economic development
}

\section{Witold Kwasnicki ${ }^{1}$ (D)}

Accepted: 21 December 2020/ Published online: 20 January 2021

(C) The Author(s) 2021

\begin{abstract}
This paper presents an evolutionary model of industry development, and uses simulations to investigation the role of diversity and heterogeneity in firms' behaviour, and hence industrial development. The simulations suggest that economic growth is increased with greater variety, in the sense of the evolutionary process approaching the equilibrium faster and also, in the long run, moving faster from one equilibrium to a new, more advanced, equilibrium. This occurs due to higher variety caused by a more tolerant environment, and due to the higher probability of emergence of radical innovations.
\end{abstract}

Keywords Tolerance $\cdot$ Diversity $\cdot$ Variety $\cdot$ Evolution $\cdot$ Fisher's theorem · Innovation

JEL codes $\mathrm{C} 63 \cdot \mathrm{D} 21 \cdot \mathrm{O} 31 \cdot \mathrm{O} 32 \cdot \mathrm{Q} 55$

\section{Introduction}

Usually when we are thinking about tolerance, two names come to mind, namely John Locke and his Letter concerning Toleration (the first publication in 1689), and Voltaire, known, among others, as the author of Treatise on Tolerance (1763). These two publications opened the European road not only for higher religious tolerance, but for general tolerance in different social dimensions. Voltaire, in his Treaty on Tolerance, asked "What is Tolerance?" and promptly answered: "It is the consequence of humanity. We are all formed of frailty and error; let us pardon reciprocally each other's folly - that is the first law of nature". Tolerance is closely related to errors, faults, deviations from something that is perceived as 'normal' or 'natural'. A tolerant sociocultural environment leads to the existence of diversity.

Witold Kwasnicki

witold.kwasnicki@uwr.edu.pl

1 Institute of Economic Sciences, University of Wroclaw, Wroclaw, Poland 
Contrary to the conviction of some human beings, tolerance and diversity ought to be associated with harmony, mutual forbearance and understanding. These virtues are noted in UNESCO's 'Declaration of Principles of Tolerance' (16 November 1995) ${ }^{1}$ where we read: "Tolerance is respect, acceptance and appreciation of the rich diversity of our world's cultures, our forms of expression and ways of being human. It is fostered by knowledge, openness, communication, and freedom of thought, conscience and belief. Tolerance is harmony in difference. It is not only a moral duty, it is also a political and legal requirement. Tolerance, the virtue that makes peace possible, contributes to the replacement of the culture of war by a culture of peace."

As Ludwig von Mises wrote in Liberalism, "what impels liberalism to demand and accord toleration is not consideration for the content of the doctrine to be tolerated, but the knowledge that only tolerance can create and preserve the condition of social peace without which humanity must relapse into the barbarism and penury of centuries long past" (2005 [1927], p. 34). Similarly, in his magnum opus, Mises states that liberal policies and tolerance are the fundamentals for innovation and technological progress: "The idea of tolerance with regard to other people's dissenting views could take root only when the liberal doctrines had broken the spell of universalism. ... These grumblers do not realize that the tremendous progress of technological methods of production and the resulting increase in wealth and welfare were feasible only through the pursuit of those liberal policies which were the practical application of the teachings of economics" (Mises 1996 [1949], p. 148 and p. 8).

Mokyr (1990) notes that "[t]echnological progress requires above all tolerance toward the unfamiliar and the eccentric", and add that "[t]he factors determining the degree of tolerance toward deviants in any society are not much understood". He generalizes that opinion in the context of 'a culture of growth'. He writes (Mokyr 2016, pp. 53 and 234): "One important cultural value is pluralism: whether to tolerate incompatible values and beliefs, and whether to give new cultural elements - no matter how outrageous they sound - a fair chance to compete in the market place for ideas and values is itself a value that needs to be accepted. A belief in cultural (including religious) tolerance and free speech and thought, and the institutions it implies (such as the first amendment to the US Constitution) can be of great economic value when it is relatively rare; it allows an economy to attract and absorb religious and political refugees, who tend to be creative and well-networked. The willingness of the Netherlands and later Britain and the United States to tolerate Jews and dissenting Christians contributed a great deal to their economies, especially in high-skilled manufacturing and financial services. ... In the market for ideas, one of the most successful ones that won out in the seventeenth century in much of Western Europe was the idea of tolerance".

Corneo and Jeanne (2009) identify tolerance with "respect for diversity", and note that tolerance "is often viewed as a distinctive feature of modern western societies".

\footnotetext{
${ }^{1} \mathrm{http} / / /$ unesdoc.unesco.org/images/0015/001518/151830eo.pdf

2 Scott E. Page in his two books on diversity (Page 2007, 2017) proves that teams of diversified people find better solutions than ingenious individuals working alone. He explains why variety is better than homogeneity, at different levels of consideration, e.g., citizens in a democracy or scientists in the laboratory. Diverse perspectives and tools enable collections of people to find better solutions and contribute to rising overall productivity. He proves that diversity (cognitive diversity as well as identity diversity) in science and engineering provides access to more talents, better solutions to challenging problems, and therefore to better science, business, and society.
} 
Cipolla describing the historical development of European Society and economy before the Industrial Revolution concludes that: "Down the centuries, those countries where intolerance and fanaticism prevailed lost to more tolerant countries that most precious of all possible forms of wealth: good human minds. The qualities that make people tolerant also make them receptive to new ideas. The influx of good minds and a receptiveness to new ideas were among the main sources of the success stories of England, Holland, Sweden, and Switzerland in the sixteenth and seventeenth centuries" (Cipolla 1993, p. 124). ${ }^{3}$

The above short review of concepts on tolerance is the general inspiration for designing a series of simulation experiments in our evolutionary model of industrial development. The model contains some general scheme of all evolutionary processes (biological, technological, economic, cultural, social, ...) based on general mechanisms of generation and selection of novelty. Our results correspond, e.g., with the observations of Melissa A. Schilling presented in her book Quirky: The Remarkable Story of the Traits, Foibles, and Genius of Breakthrough Innovators Who Changed the World. In her opinion "studying ... breakthrough innovators reveals some important commonalities that help give us insight into what made them able - and made them driven - to change the world in such dramatic ways. Although they were extremely intelligent, that is not enough to make someone a serial breakthrough innovator. Other factors played key roles. The innovators displayed some unusual characteristics - quirks - that had important implications for both the ideas they generated and the intensity with which they pursued them. For example, nearly every innovator I studied exhibited very high levels of social detachment" (Schilling 2018, p. 13-4). As our simulation experiments show, quirks are the primary sources of radical innovations, and to be frequently observed, a relatively tolerant selection environment ought to be created.

In this paper, we show how tolerance allows accelerating the emergence of innovations, technological development and economic growth. The paper is a continuation of our earlier work on 'Diversity and Development: Tempo and Mode of Evolutionary Processes' (Kwasnicka and Kwasnicki 1986). The general conclusion presented in that paper was that "the main source of improvements (innovations) is the neighborhood, not, as is commonly believed, the best elements. The existence of the neighborhood diminishes the average quality of the population; that is, it causes a worsening of system performance. ... the existence of diversity is of essential importance for long range system development seems to be intuitively acceptable, but we see a strong need for solid verification of this hypothesis."

Ronald Aylmer Fisher (1930), in his famous book The Genetical Theory of Natural Selection stated his "fundamental theorem of natural selection" as follows: "The rate of increase in fitness of any organism at any time is equal to its genetic variance in fitness at that time" and 11 years later "The rate of increase in the average fitness of a population is equal to the genetic variance of fitness of that population" (Fisher 1941).

\footnotetext{
$\overline{3}$ We find a similar opinion of Cipolla in his earlier paper (1972, p. 52) which ends: "Throughout the centuries the countries in which intolerance and fanaticism prevailed lost to more tolerant countries the most precious of all possible forms of wealth: good human brains. On the other hand, the qualities that make tolerant make them also receptive to new ideas. Inflow of good brains and receptiveness to new ideas were among the main sources of the success stories of England, Holland, and Sweden in the sixteenth and seventeenth century. It is gratifying to be able to say that tolerance pays off."
} 
Fisher's theorem has been widely discussed by biologists as well as other disciplines. In the context of evolutionary economics, the theorem was analysed by Metcalfe (1994). Metcalfe distinguishes what he calls "Fisher's principle from various forms of his fundamental theorem of natural selection". In his opinion "the principle is general and states that, in the context of a population of diverse behaviours across which selection is taking place in a constant environment, the rate of change of mean behaviour is a function of the degree of variety in behaviour across the population. ... When these behaviours are one dimensional, the principle becomes the fundamental theorem of natural selection, that the rate of improvement of mean behaviour is proportional to the variance in behaviour in the population."

What we present here is partially related to the principle stated by Fisher. As we will show, variety is essential for long-term evolutionary economic development, but there is a crucial difference between our proposition and Fisher's finding. Fisher based his consideration on the given and finite set of genotypes (solutions). We are asking to what extent the emergence of new solutions, i.e., innovations, is spurred up by variety (diversity) controlled by the selection environment. In this sense, we may say that it is the generalisation of Fisher's principle to the long-term perspective of technological development.

In the remainder of the paper, we first present shortly our existing evolutionary model, and then present a simulation study focused on the investigation of the role of diversity, tolerance and heterogeneity of firms' behaviour in industrial development, particularly related to the rate of technological development (innovativeness).

\section{The evolutionary model of industry dynamics ${ }^{4}$}

Almost all evolutionary economic models from the last decades are dynamic and are focused on far-from-equilibrium analysis. Other crucial features of the evolutionary process are not present in many models. The features that seem to be essential to call a model an evolutionary one are diversity and heterogeneity of economic agents (firms) and their behaviour, search for innovation based on a concept of hereditary information (knowledge), and a selection process which leads to a diversified rate of growth and spontaneity of development. An interesting feature of economic evolutionary models is the presence of decision-making procedures. In many models, this is not present; in some others, it has a more or less complicated form.

The firms in our model produce heterogenous products in a single market. We assume that all decisions by all firms are taken simultaneously and independently of each other, at the beginning of what we call a period. These firm decisions (e.g., on investment and selling price) depend how firms perceive the behaviour of competing firms and the expected response of the market. However, firms have limited and uncertain knowledge of the future actions of competitors is limited and uncertain, and hence decisions are boundedly rational. After decision-making, production takes

\footnotetext{
$\overline{4}$ The model is presented in more detail in Kwasnicki and Kwasnicka $(1986,1992)$ and (Kwasnicki, 1996), as well as at the website http://kwasnicki.prawo.uni.wroc.pl/?page_id=387. Examples of industry evolution in the adaptive landscape are also presented there. The simulation program was written under Turbo Pascal 7.0. in the1990s, and the software is available at http://kwasnicki.prawo.uni.wroc.pl/pliki/SourceFilesEvolModelWK. zip
} 
place and the market process takes place. How much a firm sells depends on relative prices between firms, the products' characteristics and the level of saturation of the market. In the long run, consumers prefer better products (those with lower price and better features), and firms can innovate to try to improve its position in the market by introducing innovations aimed at improving product characteristics, and lowering costs of production. The general structure of the model is presented in Fig. 1.

The product's price depends on the current technology of the firm, on market structure and on total production to be sold in the market. The two arrows between Price and Production indicate that the price is established in an interactive way to fulfil the firms' objectives (i.e., to keep relatively high profits in the near future and to assure further development in the long run). Modernization of products through innovation and/or introducing new products by applying radical innovation depends on the investment capacity of the firm. In managing innovation, the firm has to take into account economic constraints as they emerge during the firm's development, and therefore it frequently occurs a potentially prosperous invention does not reach the market.

One of the unique features of the model is the coupling of technological development and the economic processes. Current investment capacity is taken into account by each firm in the decision-making process. The success of each firm in the search for innovation depends not only on R\&D funds spent by each firm to search for innovation, but also on the extent to which firms make private knowledge public. Making the private knowledge of a firm public can, in some cases, speed up industrial development but also diminishes a firm's incentives to spend more funds on R\&D projects. We may, therefore, expect only a specific part of private knowledge to be made public.

Firms' investment capacity depends on firms' savings and available credits, and also, indirectly, on the firm's debt. Production and investment decisions are based on the firm's expectations on the future behaviour of its competitors, market structure, expected profit and the past trend of the firm's market share. Current technical and economic characteristics of products offered for sale and the technology used to manufacture the products are taken into account in the price-setting decisions, investment and production. Due to inevitable discrepancies between a firm's expectation and

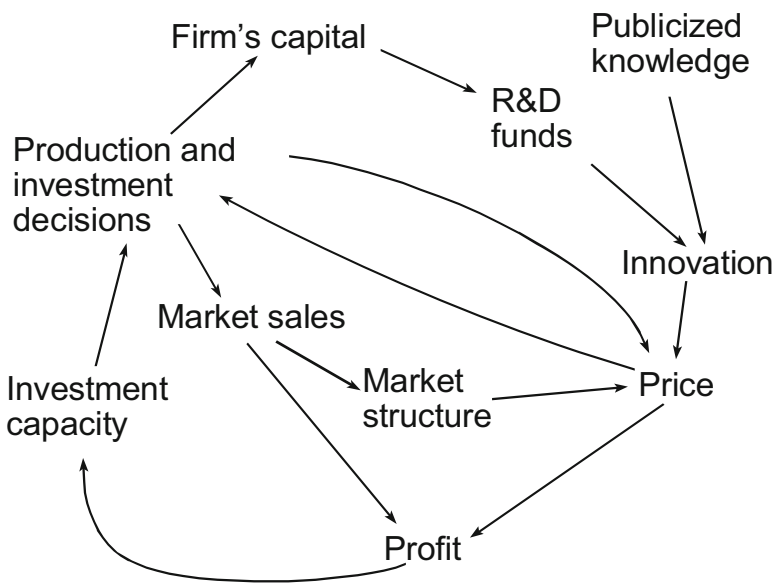

Fig. 1 General structure of the model 
real behaviour of the market, the firm's production offered for sale in the market is different from market demand (it can be either smaller or larger than demand).

We distinguish invention (i.e. a novelty being considered to be introduced into practice) and innovation (an invention introduced into the production process). There are two ways in which firms search for inventions: autonomous, in-house research, and imitation of competitors. Public knowledge allows not only for imitation of competitors, but may also concern the research process (the arrow from public knowledge to autonomous research indicates this influence). From all inventions, only a small fraction is selected to be applied. Innovation may modernize current production but can also initiate a new, radical way of production, i.e. by introducing radically new technology. In general, each innovation may reduce unit costs, increase the productivity of capital, and improve product performance. However, it frequently happens that the improvement of one factor is accompanied by deterioration of the two other. Firms, therefore, face the problem of balancing positive and negative factors of each invention. An invention will only become an innovation if positive factors prevail.

In the model, each firm may simultaneously produce products with different prices and different values of the characteristics, i.e., the firm may be a multi-unit operation. Different units of the same firm manufacture products by employing different sets of routines. Multi-unit firms exist because of searching activity. New technical or organizational solutions (i.e. a new set of routines) may be much better than the actual ones, but immediate full modernization of production is not possible because of investment constraints on the firm. In such situations, the firm continues production using the old routines and tries to open a new unit where production applying the new set of routines is started on a smaller scale. Subsequently, old production techniques may be slowly phased out.

Simulation of industry development is done in discrete time in four steps:

1. Search for innovation (i.e., search for new sets of routines that potentially may replace the old set currently employed by a firm).

2. Firms' decision making process (calculation and comparison of investment, production, net income, profit, and some other characteristics of development which may be attained by employing the old and the new sets of routines. Decisions of each firm on (a) continuation of production by employing old routines or modernizing production, and (b) opening (or not) of new units).

3. The entry of new firms.

4. Selling process (market evaluation of the offered pool of products; calculation of firms' characteristics: production sold, shares in global production and global sales, total profits, profit rates, research funds, etc.).

\subsection{The search for innovation}

The creative process is evolutionary by nature, and as such, its description should be based on a proper understanding of the hereditary information (see Kwasnicki 1996, Chapter 2). According to the tradition established by Schumpeter, and Nelson and Winter (1982), we use the term 'routine' to name the basic unit of the hereditary information of a firm. The set of routines applied by the firm is one of the primary 
characteristics describing it. To improve its position in the industry and the market, each firm searches for new routines and new combinations of routines to reduce the unit costs of production, increase the productivity of capital, and improve the competitiveness of its products in the market. Nelson and Winter (1982, p. 14) define routines as 'regular and predictable behavioural patterns of firms' and include in this term such characteristics as 'technical routines for producing things ... procedures of hiring and firing, ordering new inventory, stepping up production of items in high demand, policies regarding investment, research and development, advertising, business strategies about product diversification and overseas investment'. Routines also govern a large part of research activity. 'Routines govern choices as well as describe methods, and reflect the facts of management practice and organizational sociology as well as those of technology' (Winter 1984).

The productivity of capital, unit costs of production, and characteristics of products manufactured by a firm depend on the routines employed by the firm (examples of the product characteristics are reliability, convenience, lifetime, safety of use, cost of use, quality and aesthetic values). The search activities of firms 'involve the manipulation and recombination of the actual technological and organizational ideas and skills associated with a particular economic context' (Winter 1984), while the market decisions depend on the product characteristics and prices. We may speak about the existence of two spaces: the space of routines and the space of product characteristics.

Routines may either be active (employed by the firm in its everyday practice) or latent (stored but not applied). Latent routines may be activated at a future time. Routines belong to one of a number of different subsets, called segments, corresponding the domains of the firm's activity, such as production, managerial and organizational activity, marketing, etc. New routines may be generated by four primary mechanisms: mutation, recombination, transition and transposition. The probability of mutation (discovering a new routine) depends on the research funds allocated by the firm for autonomous research. It is assumed that routines mutate independently of each other. The scope of mutation also depends on funds allocated for in-house development.

Recombination is the discovery and imitation of routines employed by competitors, and the firm may also devote resources to facilitate this, e.g., by licensing. Recombination occurs only between segments, not between individual routines, i.e., a firm may gain knowledge about the whole domain of activity of another firm. The transmission of a single routine is called transition (see Fig. 2). After transition, a routine is latent. Finally, transposition is the activation of a latent routine (Fig. 3). It is assumed that the probabilities of the transition of a routine from one firm to another and the probabilities of the transposition of a routine (from a latent to an active routine) are independent of $R \& D$ funds, and have the same constant value for all routines.

In general, the probability of transposition of a routine for any firm is rather small. But randomly, from time to time, the value of this probability may abruptly increase, and very active processes of the search for a new combination of routines are observed. This phenomenon is called a recrudescence. Recrudescence is viewed as an intrinsic ability of a firm to search for original, radical innovations by employing daring, sometimes apparently insane, ideas. This ability is connected mainly with the personalities of the researchers, and random factors play an essential role in the search for innovations by recrudescence. Therefore the probability of recrudescence is not related 


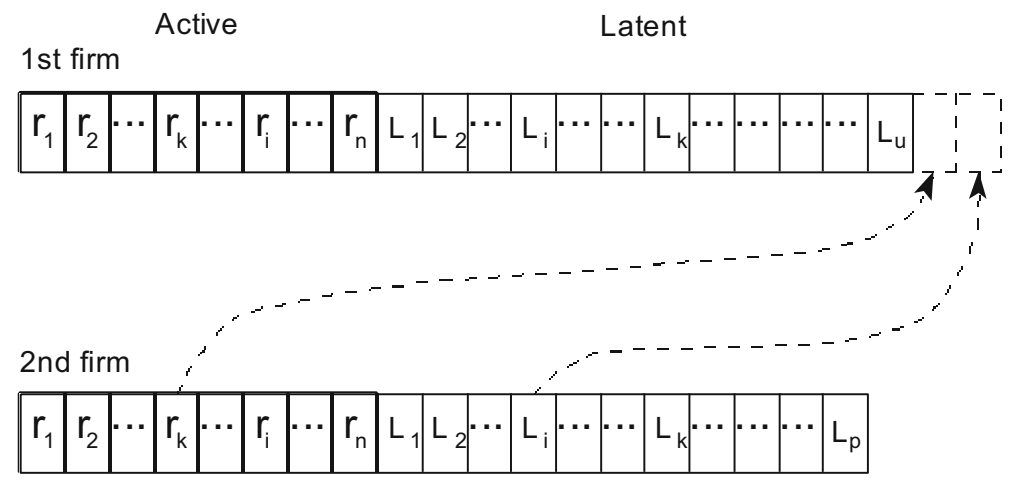

Fig. 2 Routines transition

to $R \& D$ funds allocated by a firm to 'normal' research. It is assumed that recrudescence is more probable in small firms than in large ones that spend vast quantities on R\&D.

As a rule, mutation, recombination and transposition on a normal level (that is, with low probabilities in long periods) are responsible for small improvements (gradual evolution) and, during the short periods of recrudescence, for the emergence of radical innovations.

\subsection{Firms' decisions}

One of the crucial problems of contemporary economics is to understand the process of decision-making. Herbert Simon states that 'the dynamics of the economic system depends critically on just how economic agents go about making their decisions, and no way has been found for discovering how they do this that avoids direct inquiry and observations of the process' (Simon 1986, p. 38). The background of the decisionmaking procedure adopted in the model is presented in detail in Kwasnicki (1996). It is assumed that each firm predicts the future development of the market (in terms of future average price and future average product competitiveness). Based on its expectations on future market development and expected decisions of its competitors, each firm decides on the price of its products, investment and quantity of production which it expects to sell in the market. Each firm also considers current investment capability and the possibility of borrowing.

The decision-making procedure allows modelling diversified situations faced by different firms; for example, the power of a small firm to influence the average price is much lower than that of a large firm. So, small firms are, in general, 'price takers' in the sense that they assume that the future average price will be very close to the trend value, while large firms generally play the role of 'price leaders' or 'price makers'.

A firm sets price, production and investment in such a way that some objective function is maximized. Contrary to the neoclassical assumption, it is not a

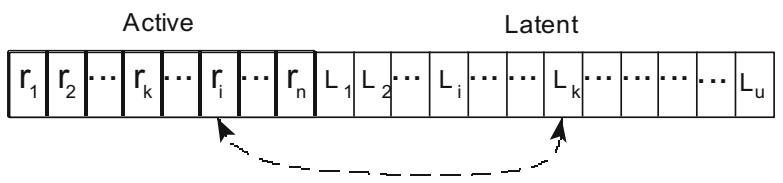

Fig. 3 Routines transposition 
maximization in the strict sense. The estimation of values of the objective function is not perfect and is made for the next period only. In other words, it is not a global, once and for all, optimization, but rather an iterative process with different adjustments taking place from period to period.

Different price-setting procedures (based on different objective functions and the mark-up rules) have been scrutinized, the results of which are presented in Kwasnicki and Kwasnicka (1992), and Kwasnicki (1996). The results of these experiments suggest that firms applying the objective $O_{1}$ function (presented below) dominate in the market and in the long run supersede all others. This objective function has the following form:

$$
\begin{aligned}
& O_{1}(t+1)=\left(1-F_{i}\right) \frac{\Gamma_{i}(t+1)}{\Gamma(t)}+F_{i} \frac{Q_{i}^{s}(t+1)}{Q S(t)}, \\
& F_{i}=a_{4} \exp \left(-a_{5} \frac{Q_{i}^{s}(t+1)}{Q D(t)}\right)
\end{aligned}
$$

where $F_{i}$ is the magnitude coefficient (with values between 0 and 1 ), $Q_{i}$ the supply of firm $i, \Gamma_{i}$ the expected income of firm $i$ at $t+1$ (defined by Eq. (2), below), $Q S$ is the global production of the industry in period $t$ and $\Gamma$ the global net income of all firms in period $t$. $\Gamma(t)$ and $Q S(t)$ play the role of constants in equation and ensure that the values of both terms in this equation are of the same order.

The expected income of firm $i\left(\Gamma_{i}\right)$ and the expected profit of this firm $\left(\Pi_{i}\right)$ are defined as

$$
\begin{gathered}
\Gamma_{i}=Q_{i}^{s}(t)\left(p_{i}(t)-V_{i} \nu\left(Q_{i}^{s}(t)\right)\right)-\eta \\
\Pi_{i}=\Gamma_{i}-K_{i}(t)(\rho-\delta)
\end{gathered}
$$

where $V$ is unit production costs, $v(Q)$ is the factor of unit production cost as a function of the scale of production (economies of scale), $\eta$ is the constant production cost, $K_{i}(t)$ the capital needed to obtain the output $Q(t), \rho$ the normal rate of return and $\delta$ the physical capital depreciation rate (amortization).

The function $O_{1}$ expresses short- and long-term thinking of firms during the decision-making process (the first and second terms in Eq. (1), respectively). Plausible values for the parameters are $a_{4}=1$ and $a_{5}=5$, implying that the long run is much more important for survival and that firms apply a flexible strategy, i.e., the relative importance of short- and long-term components changes in the course of firm's development (the long-term one is much more important for small firms than for the big ones).

\subsection{Entry}

In each period several firms try to enter the market. Each entrant enters the market with assumed capital equal to InitCapital and with the initial price of its products equal to the predicted average price. The larger the concentration of the industry, the higher the number of potential entrants (that is, firms trying to enter the market). The value of InitCapital is selected in such a way that the initial market share of an entrant is not larger than $0.5 \%$. 
In general, any firm may enter the market, and if a firm's characteristics are unsatisfactory, then it is quickly eliminated (superseded) from the market. But because of the limited capacity of computer memory for simulations, a threshold for potential entrants is assumed. It is assumed that a firm enters the market only if the estimated value of objective $O_{1}$ of that firm is greater than an estimated average value of the objective $O_{1}$ in the industry. It may be expected that a similar (rational) threshold exists in real industrial processes.

\subsection{Product competitiveness}

The productivity of capital, variable costs of production and product characteristics depend on the routines employed by a firm (see Fig. 4). Each routine has multiple, pleiotropic effects, that is, may affect many characteristics of products, as well as productivity, and the variable costs of production. Similarly, the productivity of capital, unit costs of production and each characteristic of the product can be a function of a number of routines (polygeneity).

We assume that the transformation of the set of routines into the set of product characteristics is described by $m$ functions $F_{d}$,

$$
z_{d}=F_{d}(r), d=1,2,3, \ldots, m
$$

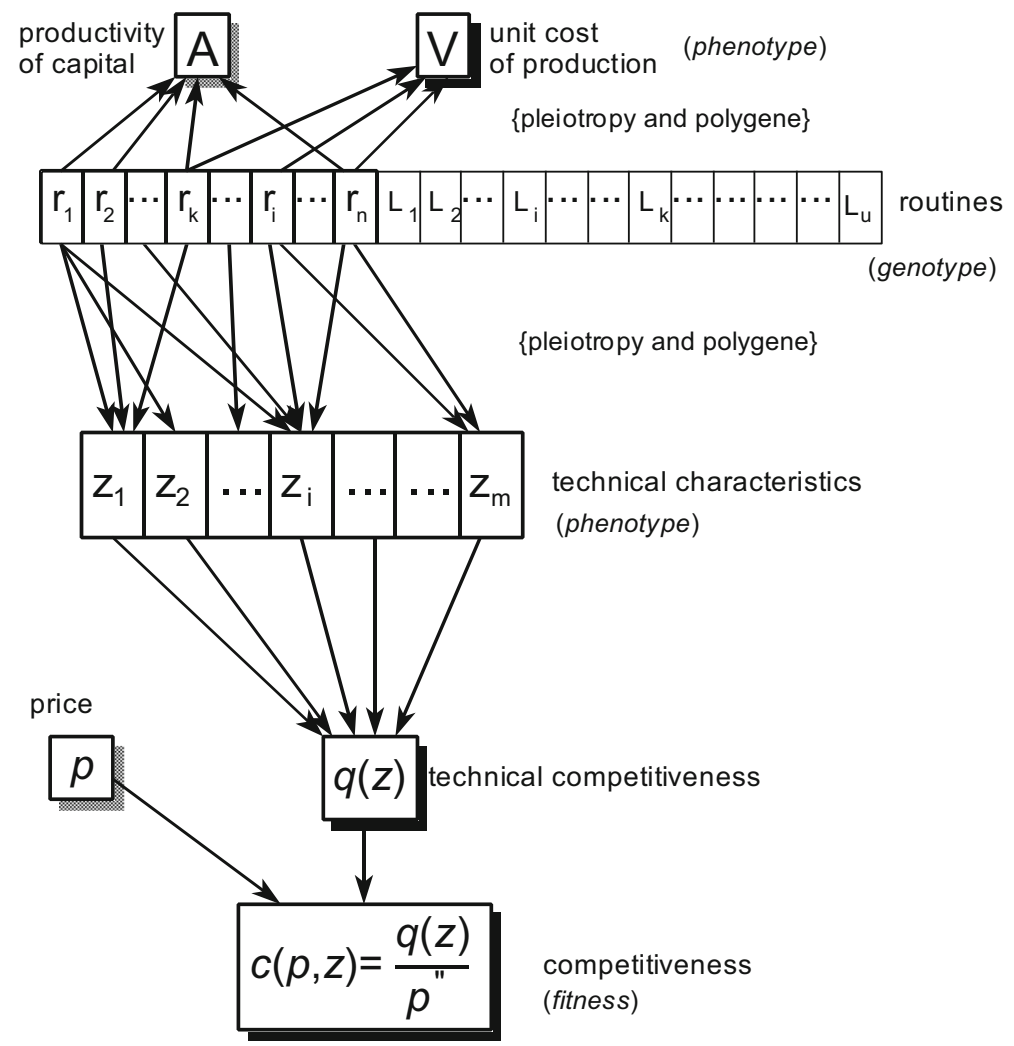

Fig. 4 From routines to competitiveness, productivity of capital and unit cost of production - from 'genotype to phenotype' 
where $z_{d}$ is the value of characteristic $d, m$ the number of product characteristics, and $r$ the set of routines. It is also assumed that the productivity of capital $A(r)$ and the unit cost of production $V(r)$ are also functions of the firm's routines, where these functions are not firm-specific and have the same form for all firms.

Attractiveness of the product in the market depends on the values of the product characteristics and its price. The competitiveness of products with characteristics $z$ and price $p$ is equal to

$$
c(p, z)=\frac{q(z)}{p^{\alpha}}, z=\left(z_{1}, z_{2}, \ldots, z_{m}\right)
$$

where $q(z)$ is the technical competitiveness, $z$ a vector of product characteristics, and $\alpha$ price elasticity.

In the presence of innovation, technical competitiveness varies according to the modification of routines made by each firm, or because of introducing radically new routines. Technical competitiveness is an explicit function of product characteristics. As explained above, each routine does not influence the product's performance directly, but only indirectly through the influence on its characteristics. We assume the existence of a function $q$, enabling calculation of technical competitiveness of products manufactured by different firms. We say that $q$ describes the adaptive landscape in the space of product characteristics. In general, this function also depends on some external factors, varies in time, and is the result of co-evolution of many related industries. The shape of the adaptive landscape depends on cultural, social and economic environments. From nature, the adaptive landscape is dynamic, with many adaptive peaks of varying altitudes. In the course of time, some adaptive peaks lose their relative importance, others become higher.

In the ongoing search process, each firm may find several alternative sets of routines. Let us denote by $r$ the set of routines applied by a firm and by $r^{*}$ an alternative set of routines. Each firm evaluates all potential sets of routines $r^{*}$, as well as the old routines $r$, by applying the decision-making procedure outlined in the former section. For each alternative set of routines, the price, production, investment (including the modernization investment), and value of objective function are calculated. The decision of firm $i$ on modernization (i.e., replacing the $r$ routines by $r^{*}$ routines) depends on the expected value of the firm's objective function and its investment capability. Modernization is undertaken if the maximum value of the objective function from all considered alternative sets of routines $r^{*}$ is greater than the value of the objective function possible by continuing the applied routines $r$, and if the investment capability of the firm permits such modernization. If the investment capability does not allow modernization, then the firm:

1. Continues production employing the 'old' routines $r$, and

2. Tries to open a new small unit where routines $r^{*}$ are applied; production is started with an assumed value of capital equal to InitCapital.

Extra investment is necessary to modernize production. This 'modernization investment' depends on the discrepancy between the 'old' routines $r$ and the 'new' routines $r^{*}$. For simplicity, it is assumed that modernization investment $I M$ is a non-decreasing 
function of the distance between the old routines $r$ actually applied by a firm and the new set of routines $r^{*}$.

All products manufactured by the entrants and the firms existing in the previous period are put on the market. All other decisions are left to buyers; these decisions primarily depend on the relative values of competitiveness of all products offered, but quantities of products of each firm offered for sale are also taken into account. It is assumed that global demand $Q^{d}(t)$ for products potentially sold on a market is equal to an amount of money $-M(t)$ - which the market is inclined to spend on buying products offered for sale by the firms divided by the average price, $p(t)$, of the products offered by these firms,

$$
Q^{d}(t)=\frac{M(t)}{p^{e}(t)},
$$

$M(t)$ is assumed to be equal to

$$
M(t)=N \exp (\gamma t)\left(p^{e}(t)\right)^{\beta}
$$

where $N$ is a parameter characterizing the initial market size, $\gamma$ the growth rate of the market, and $\beta$ the price elasticity. The average price of all products offered for sale in the market is equal to

$$
p(t)=\sum_{i} p_{i}(t) \frac{Q_{i}^{s}(t)}{Q^{s}(t)}
$$

where $Q^{s}(t)$ is global supply and is equal to

$$
Q^{s}(t)=\sum_{i} Q_{i}^{s}(t)
$$

Global production sold in the market is equal to the smaller value of demand $Q^{d}(t)$ and supply $Q^{s}(t)$

$$
Q S(t)=\min \left\{Q^{d}(t), Q^{s}(t)\right\}
$$

The selection equation describing competition among firms (products) in the market has the following form $\left(f_{i}\right.$ is the market share of products manufactured by firm $\left.i\right)$ :

$$
f_{i}(t)=f_{i}(t-1) \frac{c_{i}(t)}{c^{e}(t)}
$$

where $c(t)$ is the average competitiveness of products offered for sale, 


$$
c^{e}(t)=\sum_{i} f_{i}(t-1) c_{i}(t)
$$

This means that the share $\left(f_{i}\right)$ of firm $i$ in global output increases if the competitiveness of its products is higher than the average of all products present in the market, and decreases if the competitiveness is lower than the average. The rate of change is proportional to the difference between the competitiveness of products of firm $i$ and average competitiveness.

Finally, the quantity of products potentially sold by firm $i$ (i.e., the demand for products of firm $i$ ) is equal to

$$
Q_{i}^{d}(t)=Q S(t) f_{i}(t)
$$

The above equations are valid if the production offered by the firm exactly fits the demand in the market. These equations have to be adjusted when a discrepancy between global demand and global production exists, or a discrepancy between the demand for products of a specific firm and the production offered by this firm. The details of this adjustment process are presented in Kwasnicki (1996). The equation describes the market demand for products of firm $i$ offered at a price $p_{i}(t)$ and with competitiveness $c_{i}(t)$. In general, however, the supply of firm $i$ is different from the specific demand for its products. The realization of the demand for products of firm $i$ does not depend only on these two values of demand and supply, but on the whole pool of products offered for sale in the market. The alignment of supply and demand of all firms present in the market is an adaptive process performed in a highly iterative and interactive mode between sellers and buyers. We simulate the iterative alignment of supply and demand in a two-stage process in which a part of the demand is fulfilled in the first stage, and the rest of the demand is, if possible, fulfilled in the second stage. If there is no global oversupply of production, then in the first stage of the supply-demand alignment process all demand for production of specific firms, wherever possible, is fulfilled, but there is still the shortfall in production of firms which underestimated demand for their products. This part of the demand is fulfilled in the second stage of the supply-demand alignment process. At this stage, the products of the firms which produce more than the specific demand are sold, to replace the shortfall in production by the firms which underestimated the demand for their products.

The supply-demand alignment process is slightly different if a global oversupply of production occurs. It seems reasonable to assume that in such a case the production of each firm sold in the market is divided into (1) the production bought as the outcome of the competitive process (as described by eqs. 15 and 17), and (2) the production bought as the outcome of a non-competitive process. The latter part of production does not depend directly on product competitiveness but primarily depends on the volume of products offered for sale, i.e., random factors play a much more important role in the choice of relevant products to be bought within this part of the production. In general, the division of production of each firm into these two parts depends on the value of global oversupply. The higher oversupply, the larger is the part of the production of each firm sold based on non-competitive preferences. 
Usually, global oversupply, if it occurs, is small, so the major part of the production is distributed under the influence of competitive mechanisms, and only a tiny portion is distributed as a result of the non-competitive distribution. However, to clarify the necessity of distinguishing the two proposed stages of the selling-buying process, let us consider the following situation. Except for one firm, the production of all other firms exactly meets the demand for their products. The atypical firm produces much more than the demand for its products. It could be assumed that the production sold by all firms is precisely equal to the specific demands for their products, which is equivalent to the assumption that the quantity of overproduction of the atypical firm does not influence the behaviour of the market. In an extreme case, we may imagine that the size of production of the atypical firm is infinite and the rest of the firms continue to produce precisely what is demanded. Does this mean that the excessive production would go unnoticed by the buyers and that they would remain loyal to firms producing precisely what is demanded? An adequate description requires the incorporation of the assumption that the future distribution of products sold in the market depends on the level of overproduction of all firms, and particularly the level of overproduction of the atypical firm.

Moreover, it seems that in the case of the overproduction by one firm, its share in the global production sold will increase at the expense of all firms precisely producing what is demanded. In the extreme case, when overproduction of the atypical firm tends to infinity, the only products sold in the market belong to that firm, and the shares of all other firms will be zero. Nevertheless, it does not mean that producing more than is demanded is a profitable strategy for the firm and that it is an effective weapon to eliminate the competitors. The bulk of overproduction is not sold in the market and is lost by the firm. In effect, the atypical firm's profit is much smaller than expected or even may be negative. After some time the firm's development stops, and in the end, it would be eliminated from the market.

\section{Tolerance and adaptive landscape}

The dictionary definition of tolerance relates, among others, to an allowable deviation from a standard and the range of variation permitted in maintaining a specified characteristic. Concerning social behaviour, it refers to the ability to accept, experience, or survive something harmful or unpleasant. In the context of evolutionary processes, we may say that the selection environment can be more or less tolerant. The more tolerant the selection environment, the more it allows for coexistence of different and less competitive elements. More tolerance means that at any time, besides the best element, there exist numerous less advanced elements. In line with this interpretation of tolerance, we model a more or less tolerant selection environment by introducing different technical competitiveness functions $q(z)-$ see eq. 5 .

In order to be able to visualize the simulation results, we use a two-dimensional space of technical characteristics, $z_{1}$ and $z_{2}$. The competitiveness functions are thus an adaptive landscape $q\left(z_{1}, z_{2}\right)$, which will have only two peaks. The aim is then to show to what extent tolerance will affect the speed of climbing the adaptive hill and the possibility of finding a radical innovation on the higher adaptive peak. We propose the following shape of the adaptive landscape: 


$$
\begin{aligned}
q\left(z_{1}^{\prime} z_{2}\right)= & h_{1} e^{\text {slope }\left(\left(z_{1}+z_{2}-z_{1}^{1}-z_{2}^{1}\right)^{2}+\frac{\left(z_{1}-z_{2}-z_{1}^{1}+z_{2}^{1}\right)^{2}}{\text { tolerance }}\right)} \\
& +h_{2} e^{\text {slope }\left(\left(z_{1}+z_{2}-z_{1}^{2}-z_{2}^{2}\right)^{2}+\frac{\left(z_{1}-z_{2}-z_{1}^{2}+z_{2}^{2}\right)^{2}}{\text { tolerance }}\right)}
\end{aligned}
$$

The altitude of the lower adaptive peak $h_{1}$ is equal to 1.0 , and the altitude of the higher peak is twice of the lower one (i.e. $h_{2}=2.0$ ); the slope is equal to 0.004 , the coordinates of the first and the second peaks are equal to $\left(z_{1}^{1}, z_{2}^{1}\right)=(15,20)$ and $\left(z_{1}^{2}, z_{2}^{2}\right)=(35$, $40)$, respectively. The parameter tolerance is a positive number; the higher the value of the parameter, the more tolerant is the selection environment. The shapes of the adaptive landscape (and the contour maps) for different values of the tolerance are presented in Fig. 5. As we see, the less tolerant selection environment, the more narrow ridges of the two hills (peaks) are. The cross-section of the two peaks along the ridges does not depend on a value of tolerance and is the same for the landscapes described by the eq. (14); this cross-section (i.e., $q$ for $z_{1}=z_{2}$ ) is presented in Fig. 6. We see (Figs. 5 and 6 ) that there is a rather deep adaptive valley between the two peaks.

We performed numerous simulation experiments for the same initial conditions and different values of the tolerance parameter. In all experiments, the simulation runs started from a single firm ('a founder of the industry') manufacturing products with technical characteristics $(5,10)$. We see that the initial state of the industry is far away from both peaks. The initial 'distance' to the lower adaptive peak is equal to $(10,10)$ and to the higher peak is equal to $(30,30)$. All the time new firms can enter the market, and all incumbent firms search for inventions and introduce innovations to improve the technical performance of the products, diminished the cost of production, and increase the productivity of capital. We can expect that due to the evolutionary mechanism of searching for innovations, we will observe evolution toward the lower peak. After reaching it, firms will try to find inventions allowing jumping from the lower adaptive peak to the higher one. As our investigations show (e.g. Kwasnicki 1996), it is highly improbable that firms will reach the higher peak 'walking' along the valley (i.e., lowering the technical competitiveness of the manufactured products). Usually, due to the search for inventions through mutations, imitations and recrudescence, new and better products placed on the slope of the higher peak emerge. After that, we observe a 'march' of the firms towards the higher peak, and superseding of the products with characteristics close to the lower peak.

The question we would like to explore is how tolerance affects the speed of evolution. In all simulation experiment in the first phase, we observe the evolution of the industry (a population of firms) towards the lower peak from their initial state. In most simulations, the lower peak is reached roughly after 60 periods of evolution. At that period, a search for new (radical) invention placed on the higher peak is initiated, mainly through recrudescence, but also through recombination (imitation). In each of the runs, we record the moments of reaching specific states (the average technological competitiveness at period 20,40, and 60) along the ridge of the lower peak (along the path between initial state and the top of the hill). Next, we record the time from period 60 until the moment of finding the invention placed on the higher adaptive hill. The summary of the results is presented in Table 1 and Fig. 7. We selected 11 values of the 
a

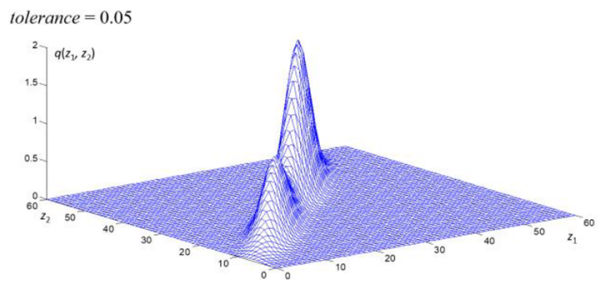

tolerance $=0.2$

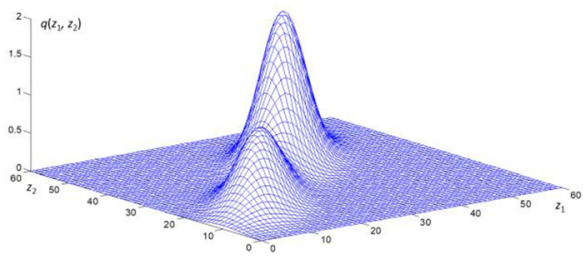

tolerance $=0.5$

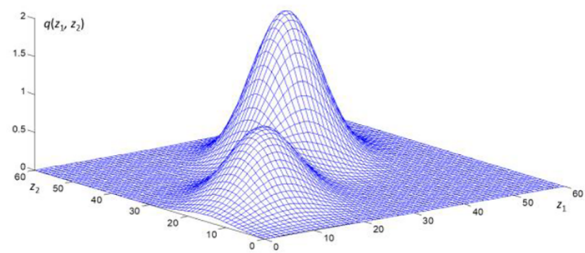

b

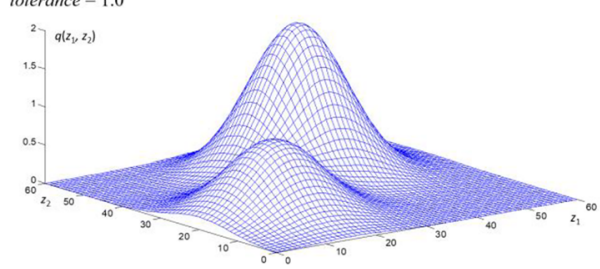

tolerance $=2.0$

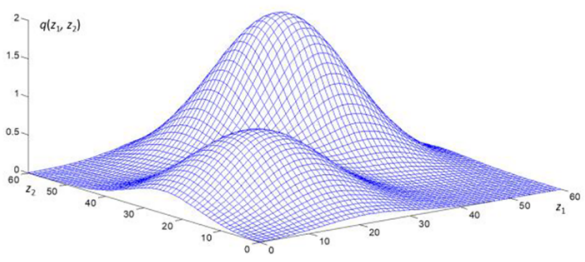

tolerance $=5.0$

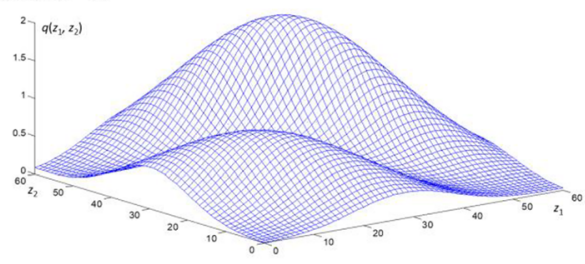

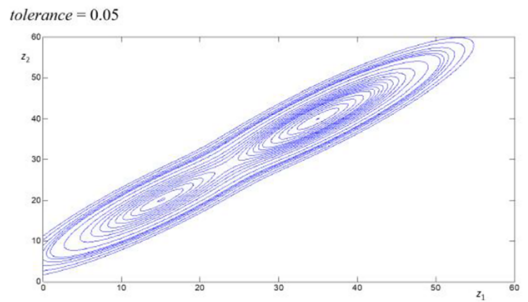

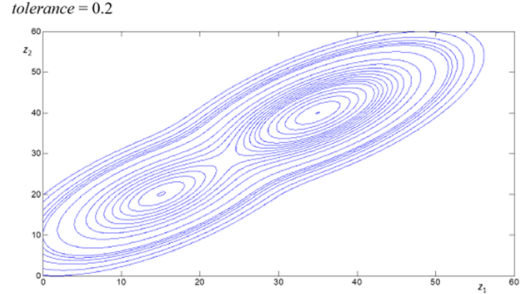

tolerance $=0.5$
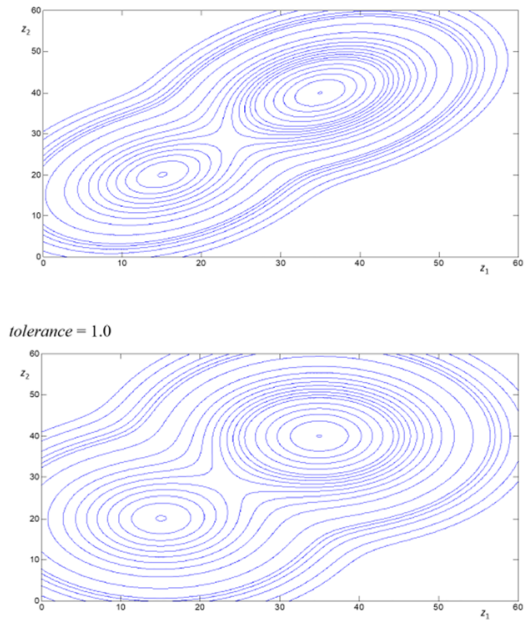

tolerance $=2.0$

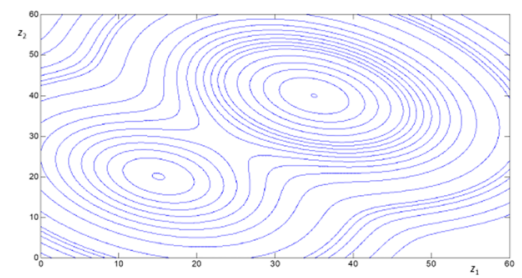

tolerance $=5.0$

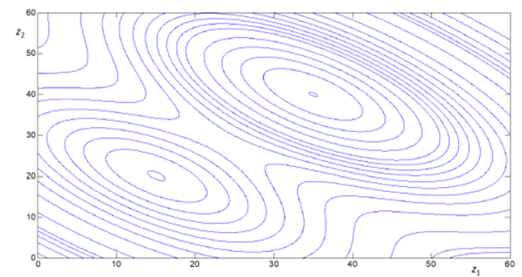

Fig. 5 The shapes and the map of the adaptive landscapes for different values of the tolerance parameter 


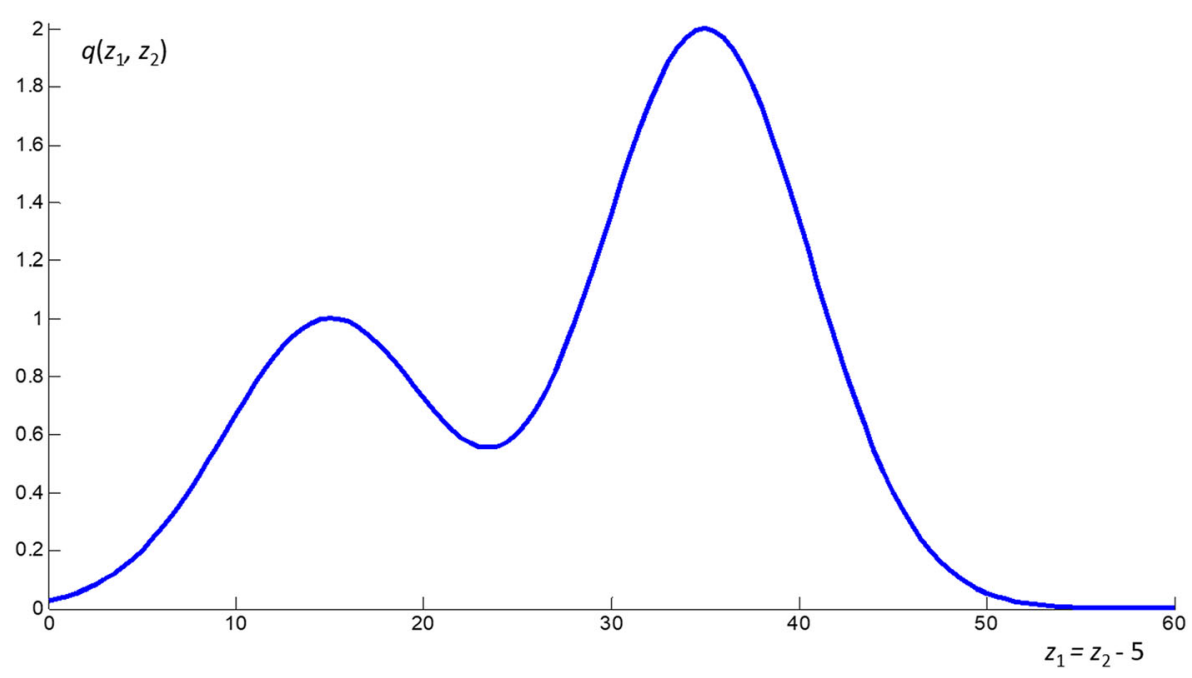

Fig. 6 The cross-section of the two peaks along the ridge

tolerance parameter (ranging from 0.01 up to 100), and for each value, we carried out ten simulation experiments. The average values of the technical competitiveness and maximum values of the technical competitiveness (frontiers of the research) at periods 20, 40, and 60 are presented in Fig. 7.

We see that there is a strong relationship between tolerance and the speed of evolution, with a more tolerant selection environment associated with quicker evolution towards the lower peak. ${ }^{5}$ This is caused by the higher diversity of products (innovations) manufactured by the firms (see, e.g. Figs. 13, 14, 15) in the more tolerant selection environment. Thanks to the higher diversity, it is easier to find better solutions (invention) due to imitation (recombination) as well as due to autonomous research of the firms (mutation). For low values of the tolerance parameter $(0.01,0.02)$, evolution is very slow and almost stops halfway to the lower peak in the first 60 periods of evolution.

A much stronger influence of tolerance is observed in the second phase of the evolution, i.e., the search for the radical invention placed on the higher adaptive hill. The waiting times for the emergence of the radical innovation placed on the higher peaks for all simulation runs are presented in Table 1 and Fig. 8. Due to limitations in the simulation software, simulations are limited to 200 periods. It turns out that for a number of runs with low tolerance, 200 periods is not enough to climb the higher peak. Those unsuccessful runs are marked by question marks (?) in Table 1. Naturally, for those runs, it was not possible to calculate the average waiting time, but in general, it is clearly visible that the higher the tolerance of the selection environment the quicker the radical innovation emerges.

Two phenomena play an important role in this process: (1) the more intolerant the selection environment is, the smaller is the area with high values of technical

\footnotetext{
${ }^{5}$ We should also think in terms of 'boundaries of toleration' (Stepan and Taylor 2014). A higher level of tolerance leads to quicker long-run evolution but also leads to diminishing current average quality of 'performance' of the system.
} 
Table 1 Waiting times for jumping to higher peak in the adaptive landscape

\begin{tabular}{|c|c|c|c|c|c|c|c|c|c|c|c|}
\hline & \multicolumn{11}{|c|}{ Tolerance } \\
\hline & 0.01 & 0.02 & 0.05 & 0.1 & 0.2 & 0.5 & 1 & 2 & 5 & 10 & 100.0 \\
\hline run1 & $?$ & 80 & $?$ & 125 & 76 & 40 & 52 & 9 & 44 & 13 & 16 \\
\hline run2 & $?$ & $?$ & 35 & 44 & 29 & 9 & 6 & 70 & 20 & 17 & 38 \\
\hline run3 & 34 & $?$ & $?$ & 40 & 9 & 25 & 16 & 18 & 2 & 4 & 8 \\
\hline run4 & 117 & 68 & $?$ & 43 & 22 & 48 & 53 & 9 & 22 & 11 & 36 \\
\hline run5 & $?$ & 87 & $?$ & 118 & $?$ & 51 & 15 & 10 & 3 & 3 & 7 \\
\hline run6 & $?$ & $?$ & $?$ & $?$ & 38 & 61 & 56 & 49 & 3 & 4 & 2 \\
\hline run7 & $?$ & $?$ & 20 & 10 & 125 & 35 & 4 & 43 & 21 & 12 & 30 \\
\hline run8 & $?$ & $?$ & $?$ & 131 & $?$ & 8 & 50 & 31 & 22 & 22 & 9 \\
\hline run9 & $?$ & 136 & 130 & 48 & 29 & 12 & 37 & 10 & 9 & 11 & 10 \\
\hline run10 & 80 & $?$ & 114 & 94 & 125 & 7 & 10 & 4 & 37 & 12 & 5 \\
\hline Avarage & - & - & - & - & - & 29.6 & 29.9 & 25.3 & 18.3 & 10.9 & 16.1 \\
\hline St. dev. & - & - & - & - & - & 20.1 & 21.6 & 22.1 & 14.4 & 6.0 & 13.4 \\
\hline
\end{tabular}

competitiveness of the radical innovation placed on the second adaptive peak, and (2) for higher tolerance, the average competitiveness is smaller than the maximal potential competitiveness (due to higher diversity) and the selection environment 'eagerly accepts' radical innovation (placed on the second peak) with lower technical competitiveness (see Eq. 11). The results presented in Table 1 and Fig. 8 show great variety of the waiting time within identical values of the tolerance parameter, e.g., for the tolerance equal to 0.5 the shortest waiting time is seven periods, and the longest is 61 periods, the average waiting time is equal to 29.6 periods, and the standard deviation is equal to 20.1 .

In Figs. 9, 10, and 11, the trajectories of development (defined by the average values of both technical characteristics $\left(z_{1}, z_{2}\right)$ for all periods from zero to 200) are presented for three selected values of the tolerance parameter. It is seen that for low tolerance, the diversity of trajectories is small (all ten trajectories are very close to each other), and the higher tolerance, the more diversified trajectories are.

To illustrate the second phase of the industry evolution (jumping from the lower to the higher adaptive peak) in the next few figures, we present the industry states for specific periods. ${ }^{6}$ The industry state in the simulation experiment for medium tolerance (1.0) in a period of emergence of the radical innovation (period 62) is shown in Fig. 12. This radical innovation is marked by the red star on the higher peak. All other firms (products) are still placed on the lower peak. It is worth noticing that that the innovation differs radically from all other products in terms of the technical characteristics $\left(z_{1}^{1}, z_{2}^{1}\right)$. Still, the technical competitiveness is smaller than that of all other incumbent products (firms). It was accepted due to its advantages in terms of the cost of production

\footnotetext{
${ }^{6}$ The presented illustration also shows widespread phenomenon observed in the history of evolutionary processes (history of ideas, history of technological innovation, industrial development, ...). There are numerous examples of rediscoveries and reinventions, i.e. emergences of some ideas and their disappearance, to be rediscovered by someone else later on (it relates to so-called Stigler's law of eponymy).
} 

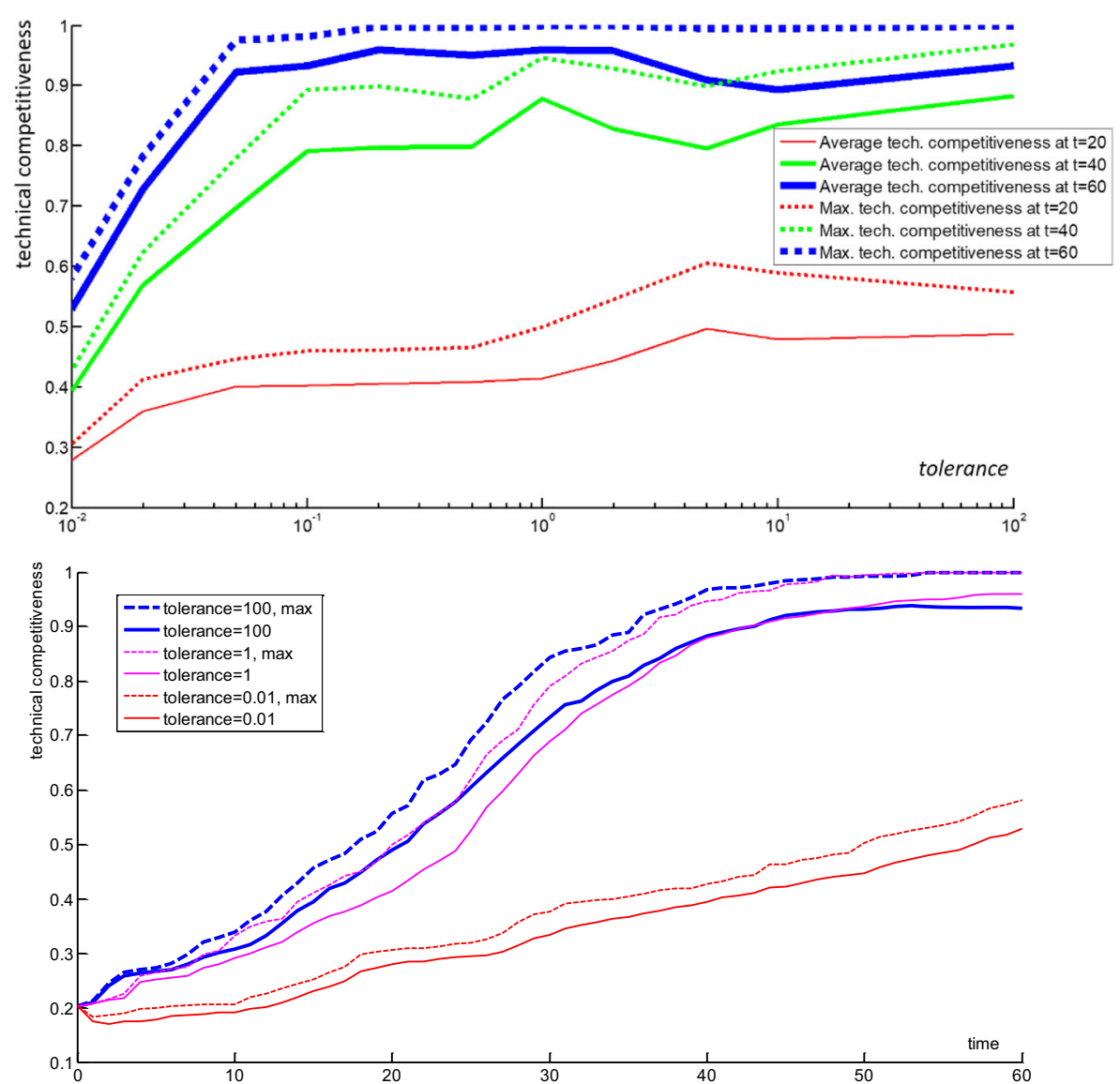

Fig. 7 Technical competitiveness reached at different times for different tolerance levels (upper graph), and the evolution toward the first (lower) peak (lower graph) - average values of technical competitiveness out of ten runs

and the efficiency of applied capital (relatively low cost of production and high productivity of capital). In the following periods (63 to 66), the innovation has been

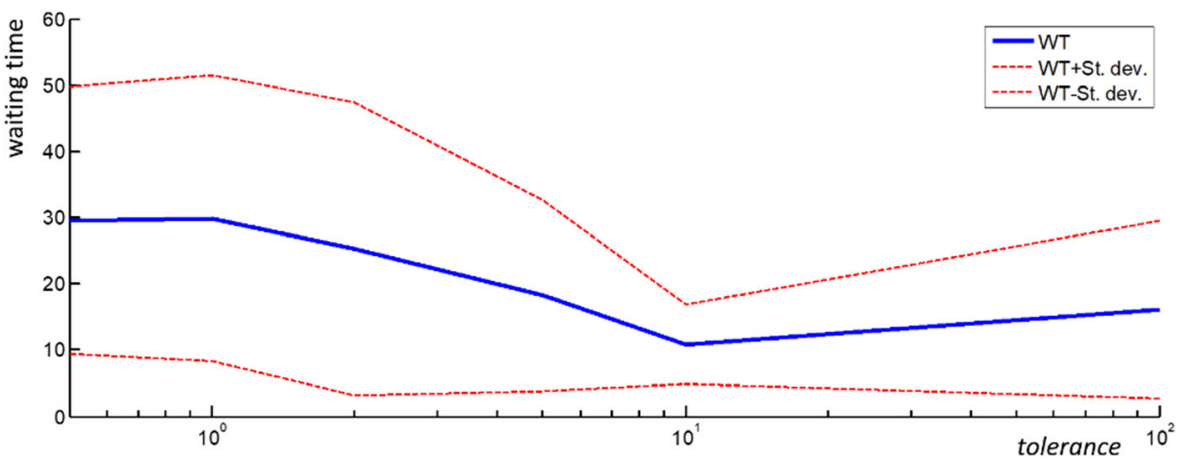

Fig. 8 The average waiting time for radical innovation emergence (and its standard deviation) for different values of the tolerance parameter 

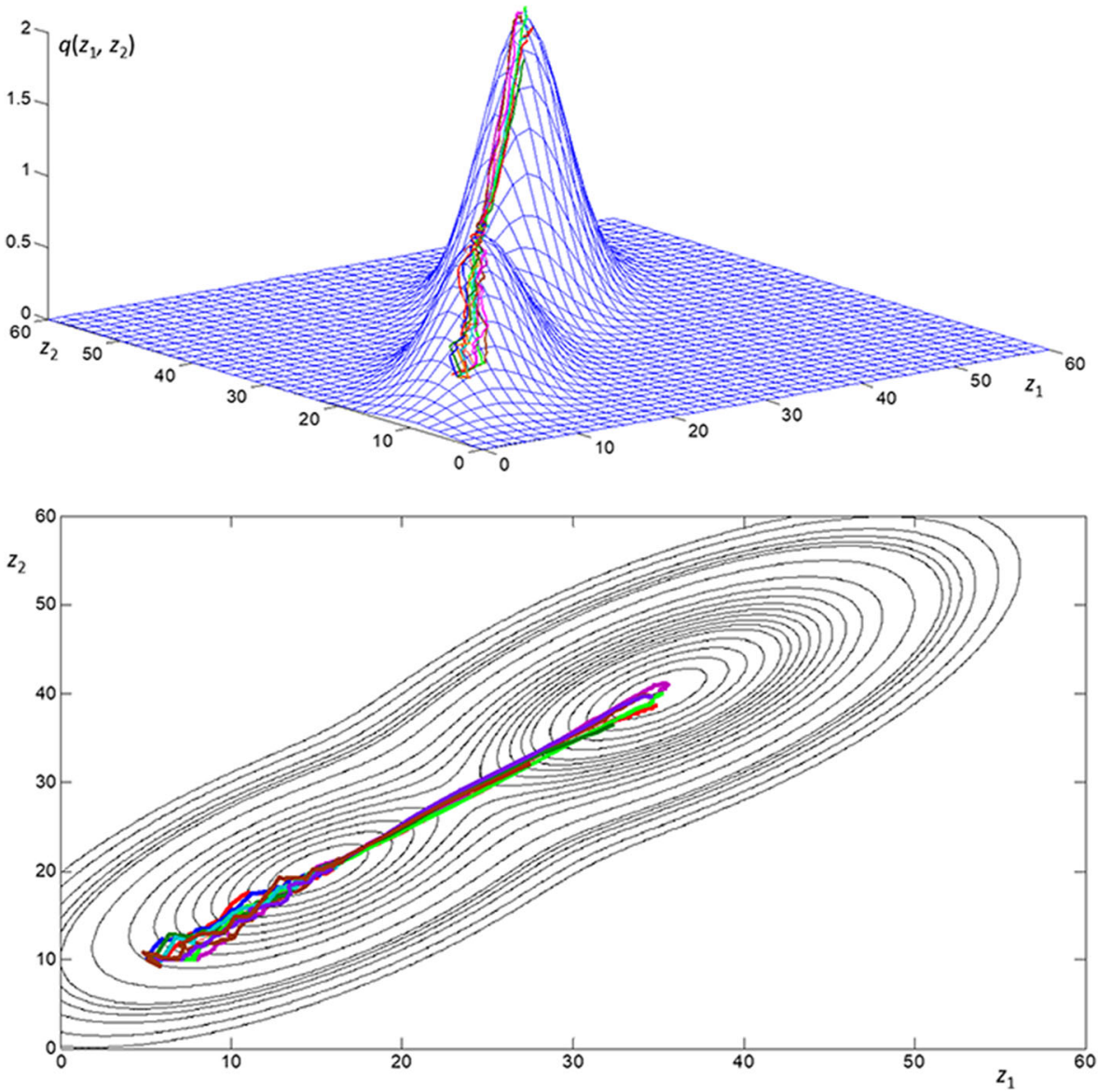

Fig. 9 Trajectories of development for 10 simulation runs $($ Tolerance $=0.2$ )

developed and the evolution toward the higher peak has been initiated (see two first maps for $t=64$ and $t=66$ in Fig. 13), but also other firms have made concurrent improvements of the incumbent products and the radical innovation was superseded from the market. In period 67 there was no innovation placed on the higher peak (see the third map in Fig. 13, for $t=67$ ). The search process by all firms has been going on, and after three periods, another radical innovation emerged in the higher peak (see the fourth map in Fig. 13). It was a successful innovation, and in the next periods the new firms imitated and improved that innovation so more and more firms manufactured products placed on the higher peak, closer and closer the to the maximum of the hill (see the next maps in Fig. 13 for $t=85,100$, and 130, respectively). As we see after 60 periods from the initial radical innovation, in the period 130, the whole industry is placed on the higher peak. 

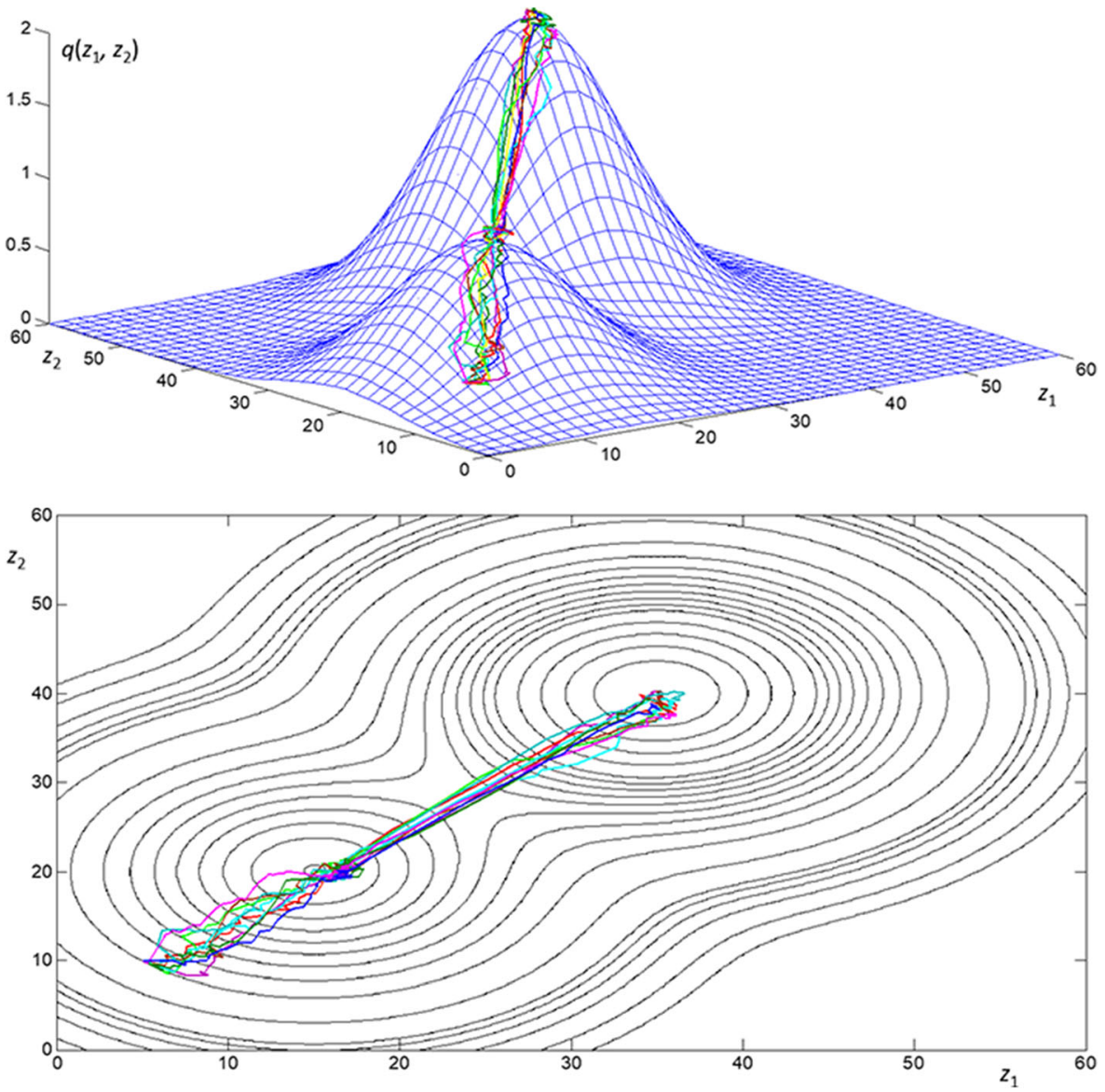

Fig. 10 Trajectories of development for 10 simulation runs $($ Tolerance $=1.0$ )

To show the difference in the mood of evolution for a less tolerant selection environment (tolerance $=0.2$ ) and a more tolerant environment (tolerance $=5.0$ ), a series of maps illustrating the emergence of radical innovation are presented in Figs. 14 and 15 , respectively. One general observation is that for low tolerance the diversity of firms (seen, e.g. in terms of the size of the 'cloud' of firms) is much lower than in the previous experiment (tolerance $=1.0$ ). For higher tolerance, diversity is much higher.

\section{Conclusions}

In our model of industrial development, a tolerant selection environment fosters higher diversity, and also a temporary lowering of average competitiveness of incumbent products. However, this brief, local deterioration of competitiveness is compensated by 

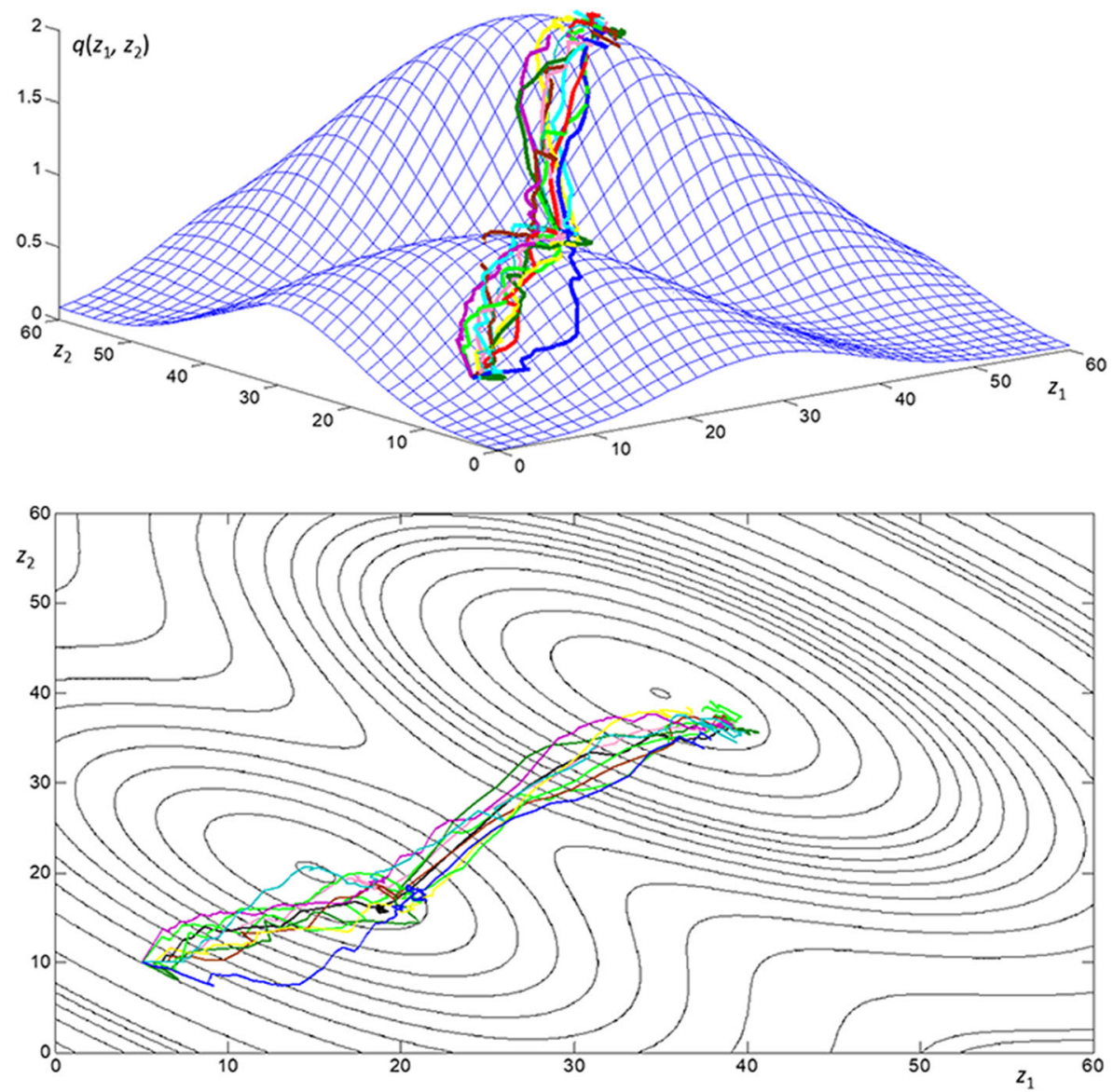

Fig. 11 Trajectories of development for 10 simulation runs $($ Tolerance $=5.0)$

much quicker long-term development. Therefore, high tolerance seems to be advantageous for general, long-term evolution. 'The adaptive landscape' is a focal notion used in this paper. From nature, the adaptive landscape is dynamic, with many adaptive peaks of varying altitudes. The shape of the adaptive landscape depends on cultural, social and economic environments; therefore, we can say that the tolerance level also depends on cultural, socio-political and economic systems.

The simulation results suggest that Schumpeter (2006, p. 83) was right expressing the opinion that "A system - any system, economic or other - that at every given point of time fully utilizes its possibilities to the best advantage may yet in the long run be inferior to a system that does so at no given point of time, because the latter's failure to do so may be a condition for the level or speed of long-run performance" (emphasis in the original). Paolo Saviotti in his book on Technological evolution, variety, and the economy (Saviotti 1996) gives additional evidence that diversity, variety are essential factors for proper technological development. 

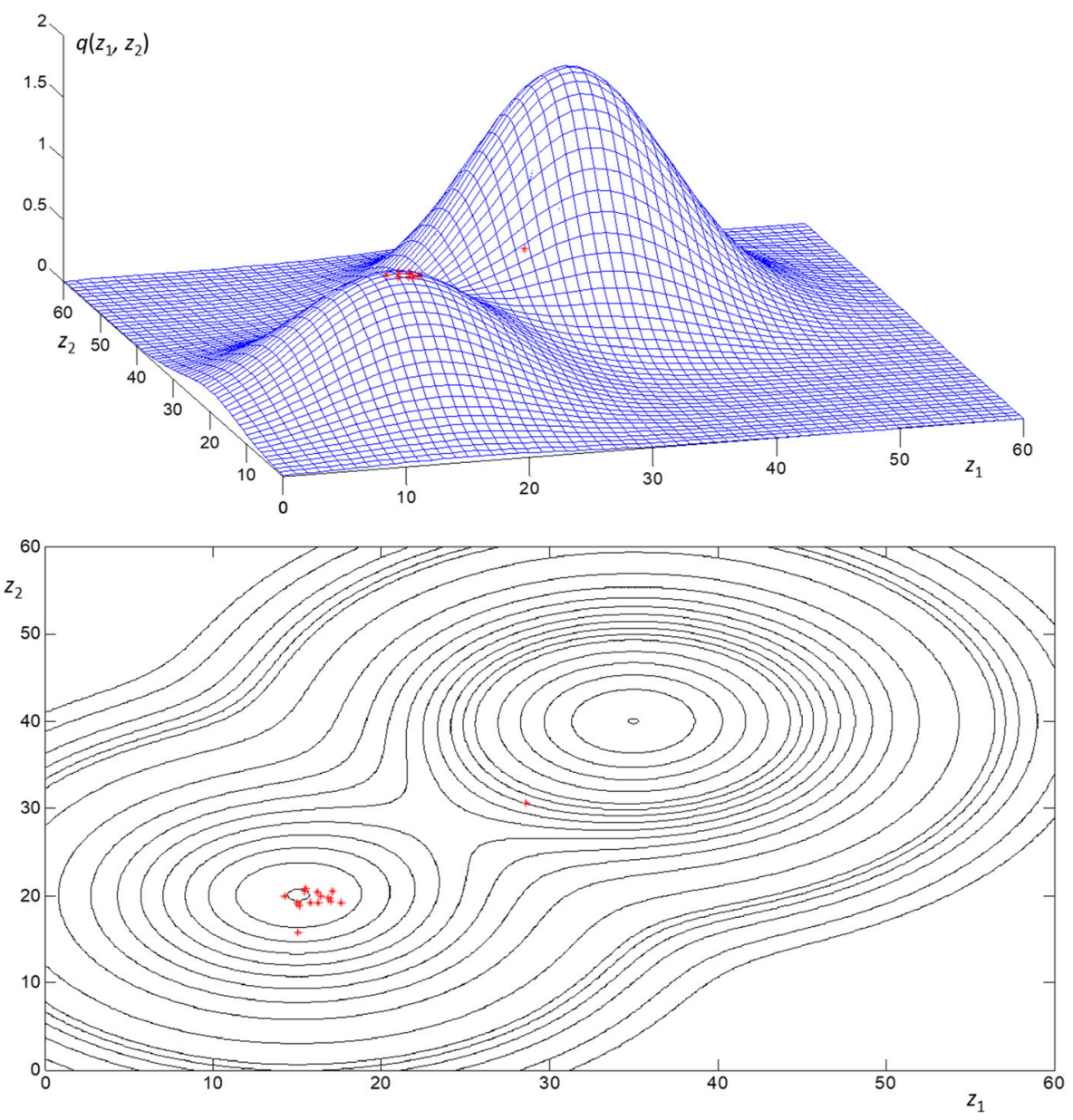

Fig. 12 Emergence of the first radical innovation in period 62 for run 10, Tolerance $=1.0$ )

Good examples of social environments with high tolerance and the related emergence of radical new ideas are Edinburgh in the eighteenth century and Vienna in the turn of the 19th and 20th centuries. Edinburgh was at the heart of the Scottish Enlightenment in the eighteenth century. The Enlightenment culture was based on tolerance and openness for new ideas. It took a form of close readings of new books, and intense discussions at numerous intellectual gathering places in Edinburgh. Intellectual life revolved around several clubs emerging at the beginning of the eighteenth century. One of the first and highly influential were the Easy Club and the Political Economy Club, aimed at creating links between academics and merchants. The younger Allan Ramsay, a prominent artist, and philosophers David Hume and Adam 
$t=64$

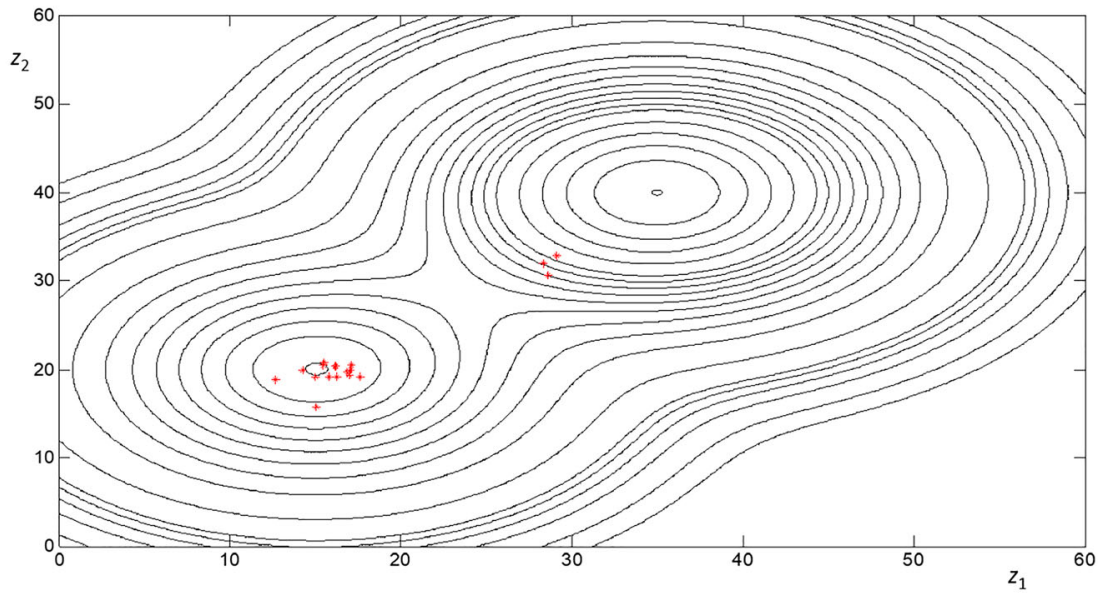

$t=66$

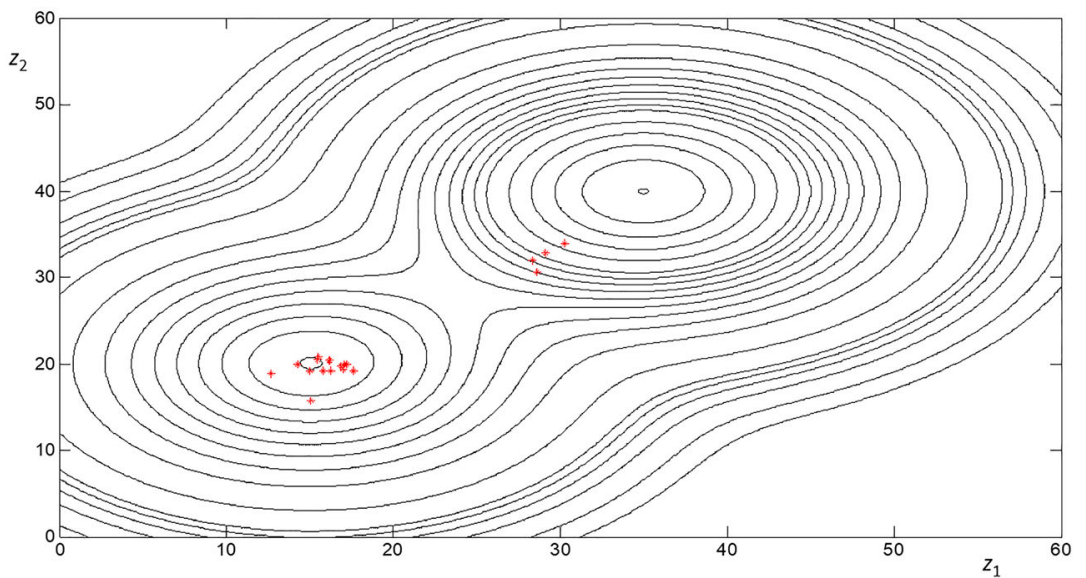

$t=67$

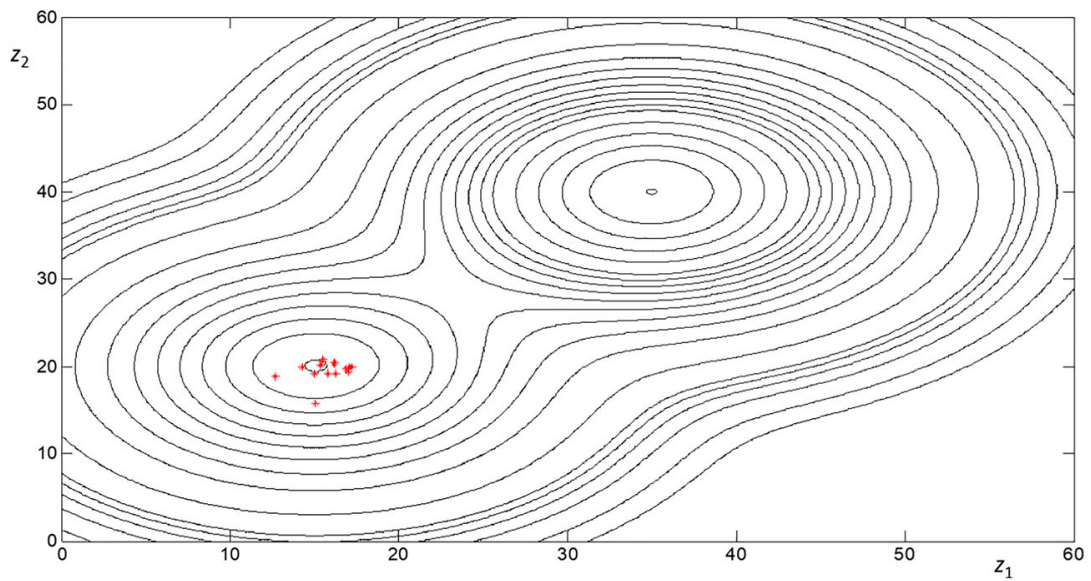

Fig. 13 Sequence of innovation for run $10($ Tolerance $=1.0)$, for selected periods 


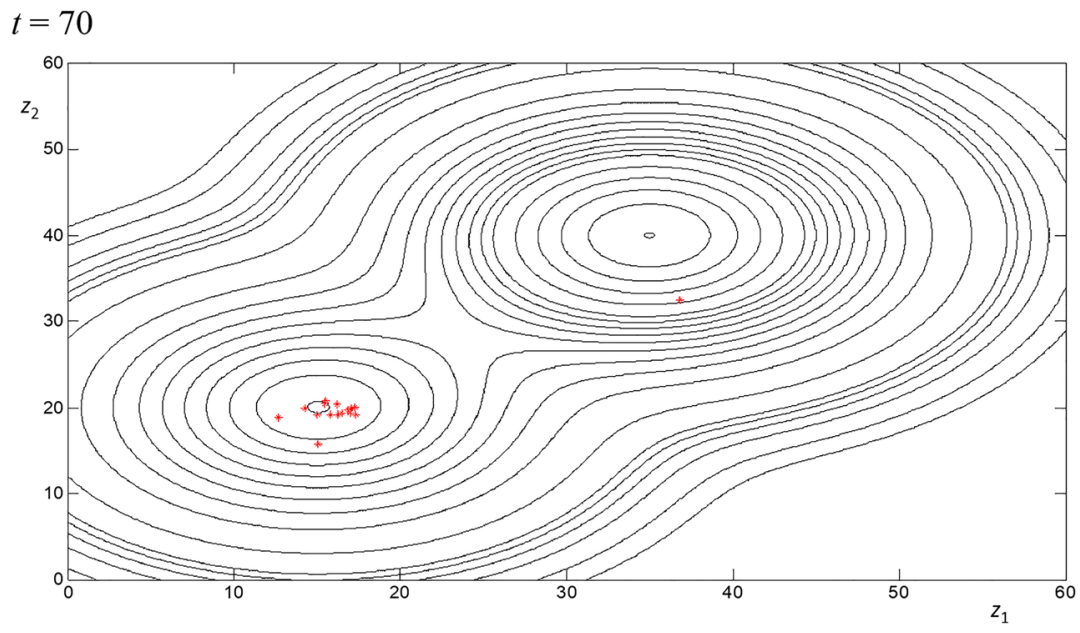

$t=85$

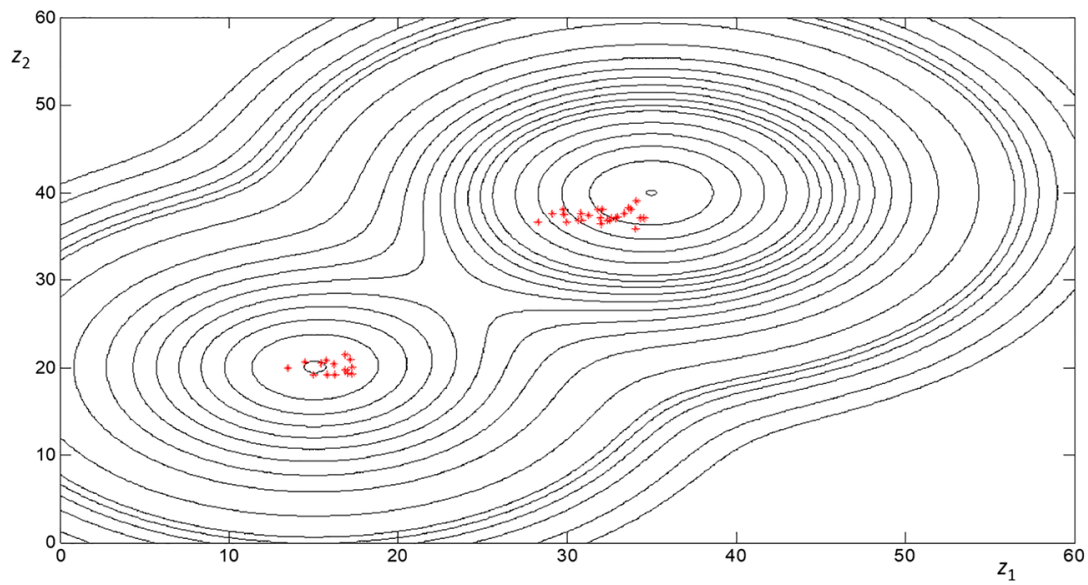

$t=100$

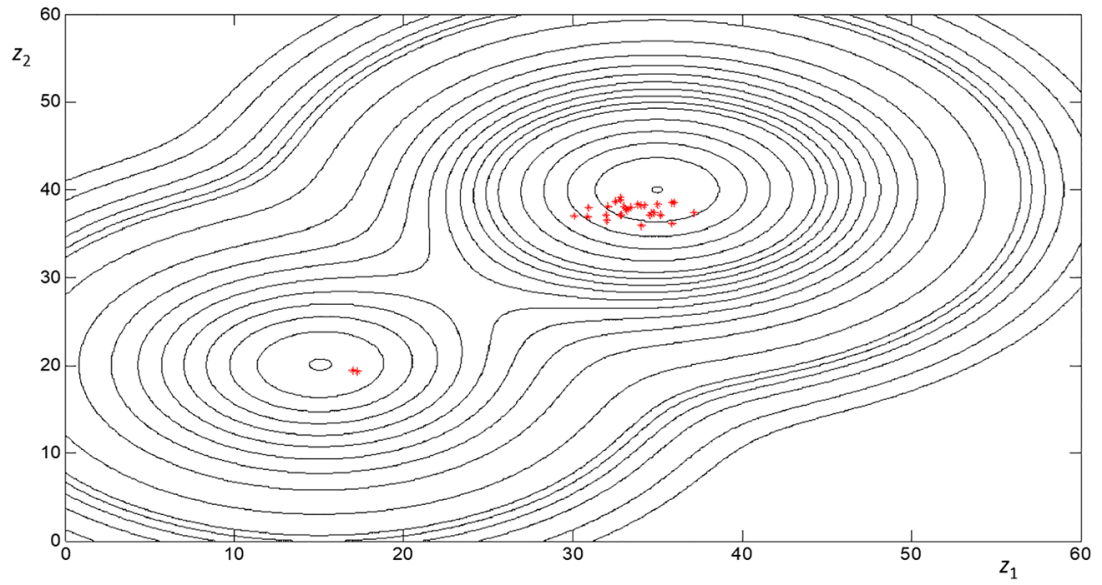

Fig. 13 (continued) 


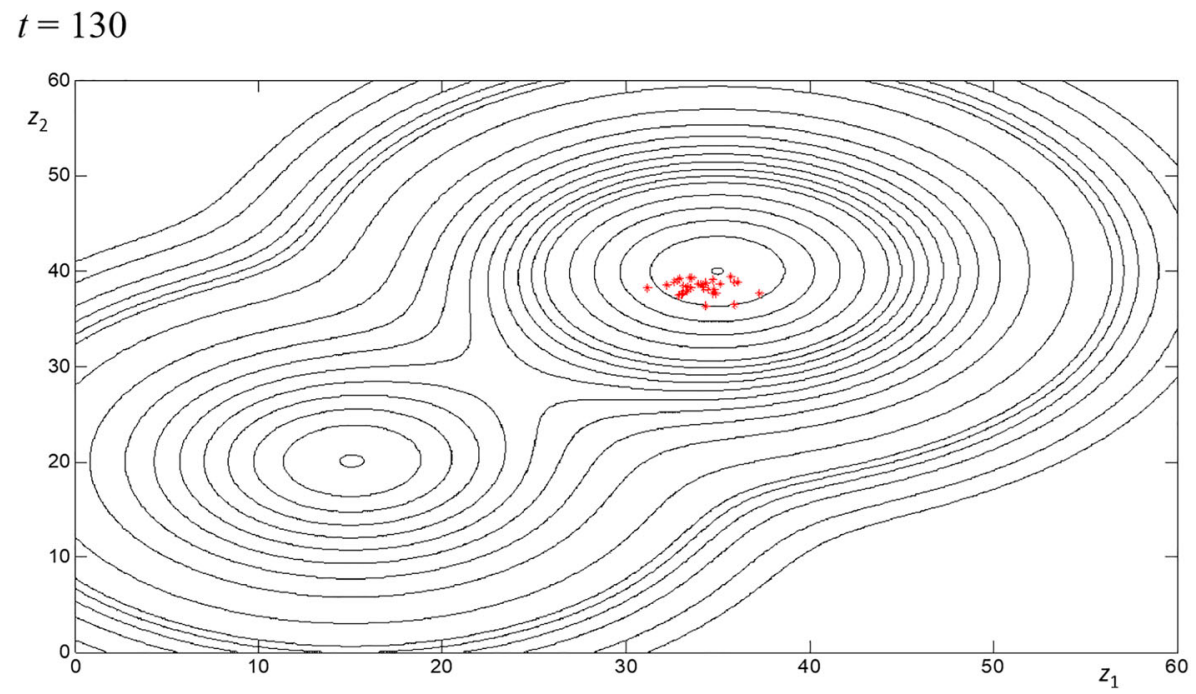

Fig. 13 (continued)

Smith formed The Select Society. One of the most notable was, established in 1762, The Poker Club. Adam Ferguson proposed the name for the aim to "poke up" opinion on the militia issue.

Colin Macfarquhar, Andrew Bell, and others, designed Encyclopcedia Britannica in Edinburgh. It was first published in three volumes between 1768 and 1771, with 2659 pages and 160 engravings. Encyclopaedia Britannica became a standard reference work in the English-speaking world. The fourth edition (1810) ran to 16,000 pages in 20 volumes. The Encyclopaedia continued to be published in Edinburgh until 1898. Among the fields that rapidly advanced in Edinburgh were philosophy, political economy, engineering, architecture, medicine, geology, archaeology, law, agriculture, chemistry and sociology. The development of these sciences is closely related with such Edinburgh thinkers like Francis Hutcheson, George Turnbull, David Hume, Adam Smith, James Hutton, Dugald Stewart, James Beattie, Robert Burns, Adam Ferguson, John Playfair, Joseph Black, James Hutton, and William Robertson. Edinburgh became a major intellectual centre, earning it the nickname "Athens of the North", also because of its many neo-classical buildings and reputation for heated discussions and learning, recalling ancient Athens.

Almost the same may be said about the tolerance environment in Vienna under the reign of Franz Joseph I, who was Emperor of Austria and King of Hungary from 1848 to his death in $1916 .^{7}$ In the second half of the 19th Vienna was a kind of cultural melting pot consisting of Italians, Slovaks, Poles, Slovenians, Moravians, Germans, and Czechs. Vienna was the cradle of modernism and fascism, liberalism and totalitarianism. It is enough to mention the ideas and art brought forth during the fertile

\footnotetext{
7 'How Vienna produced ideas that shaped the West', The Economist, Dec 24th 2016 (http://www.economist. com/news/christmas-specials/21712044-city-century-how-vienna-produced-ideas-shaped-west)
} 

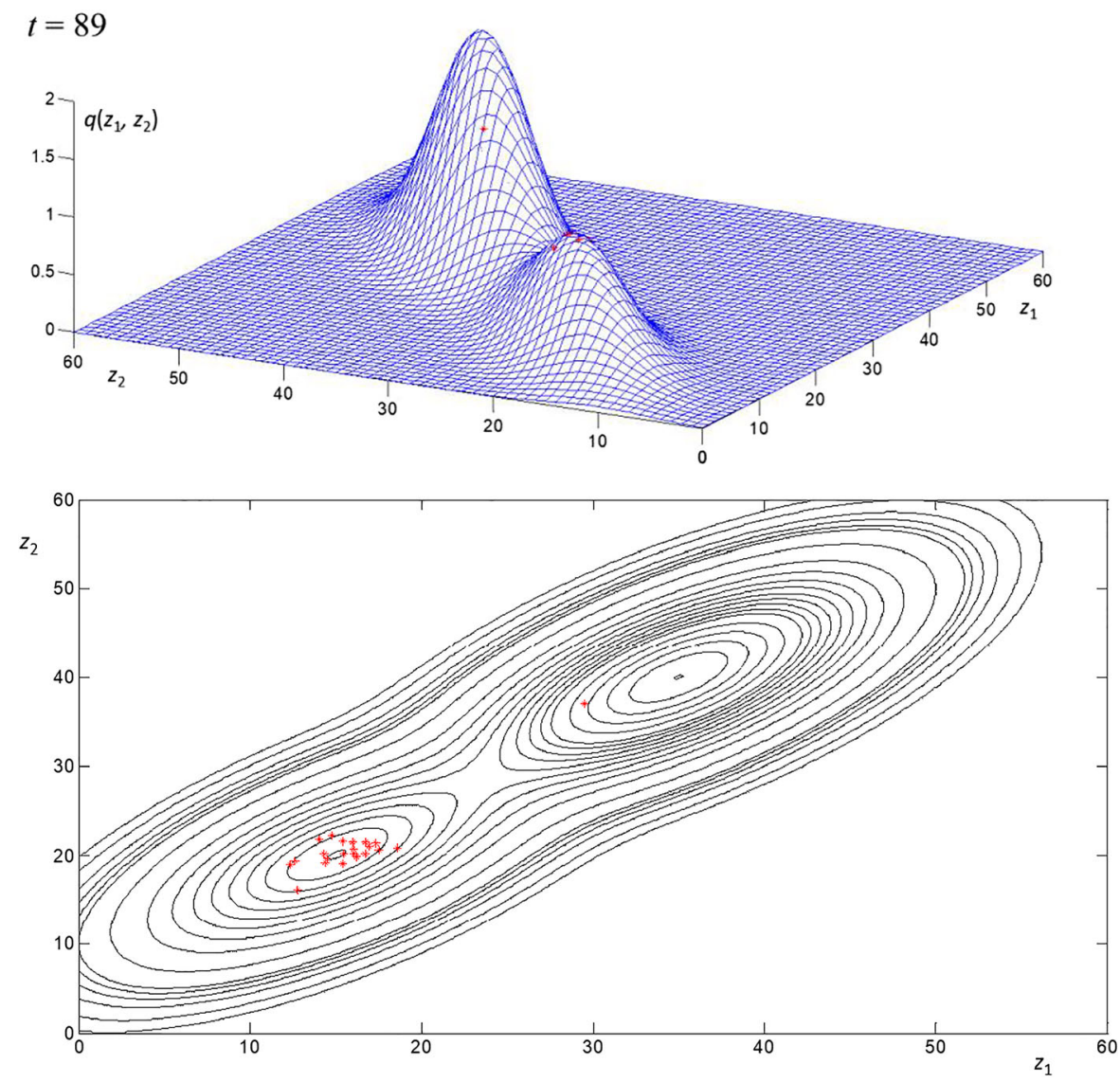

$t=104$

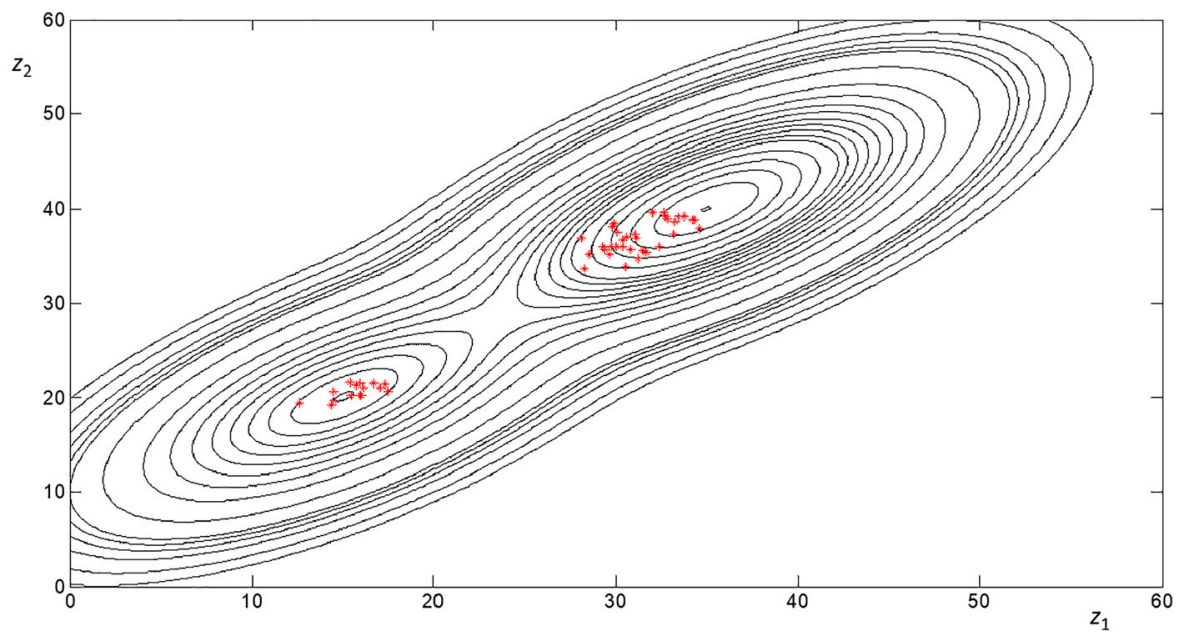

Fig. 14 Sequence of innovation for run 1 (Tolerance $=0.2$ ), for selected periods 


$$
t=119
$$

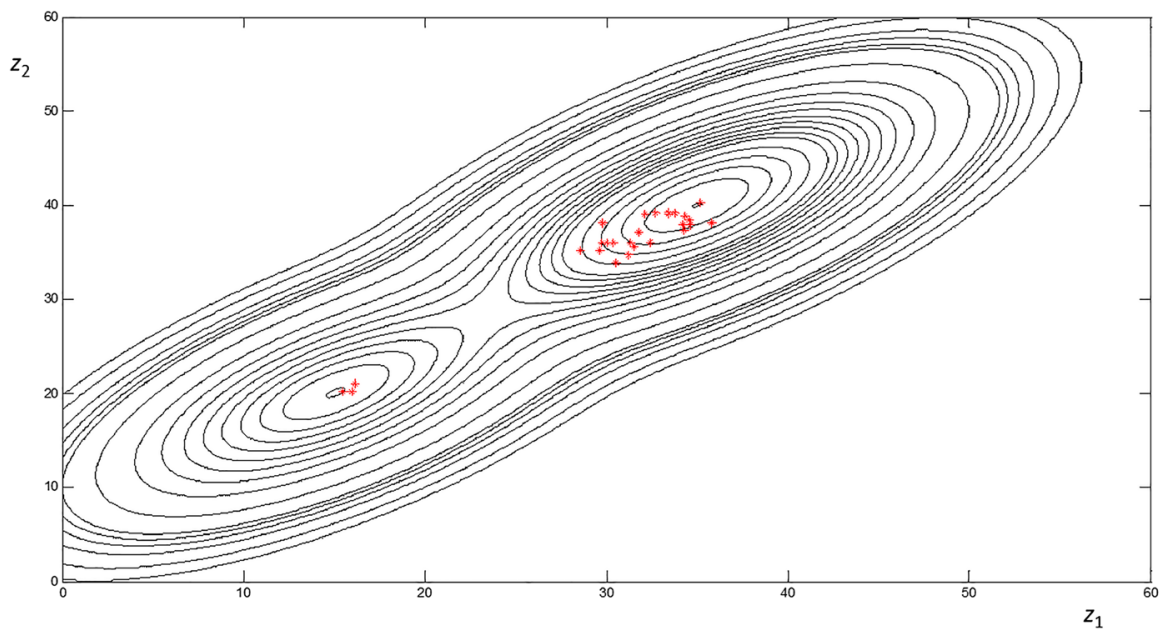

$$
t=149
$$

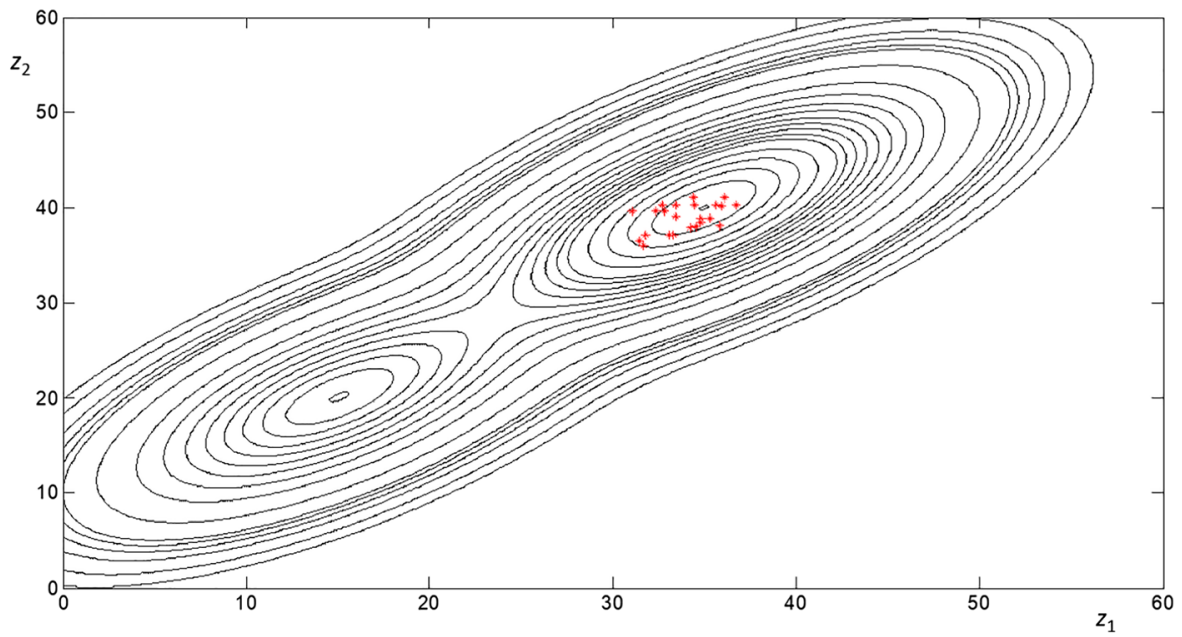

Fig. 14 (continued)

period of Viennese history from the 1870s to the 1920s endured, starting from Adolf Loos's modernist architecture, through Arnold Schönberg's atonal music and Gustav Mahler's 'Sturm und Drang', Psychopathia Sexualis by Richard von Krafft-Ebing, revolutionary economic ideas of Carl Menger (founder of the Austrian school in economics: Eugen von Böhm-Bawerk, Ludwig von Mises, Joseph Alois Schumpeter, Friedrich August von Hayek), psychoanalysis of Sigmund Freud, Gustav Klimt's symbolist canvasses and avant-garde artistic projects of the day, such as the Vienna Secession movement of 1897, ending by Ludwig Wittgenstein's philosophy and the Vienna Circle of Logical Empiricism. 
$t=104$

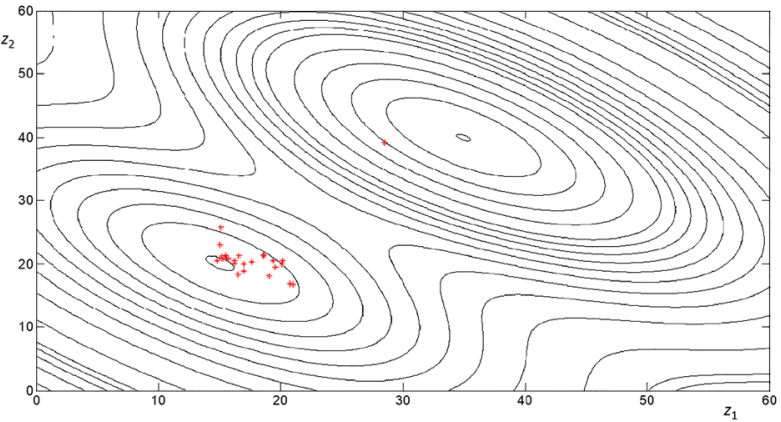

$t=119$

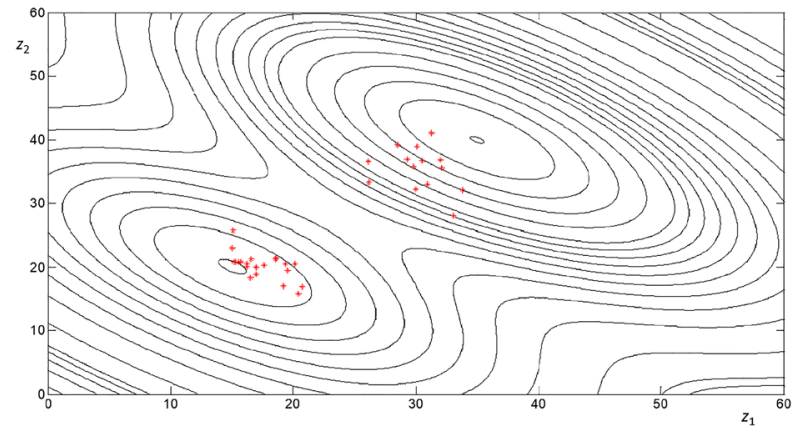

$t=134$

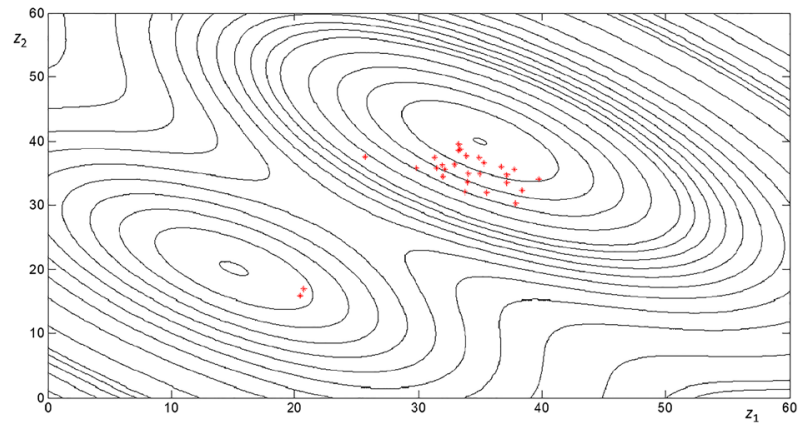

$t=164$

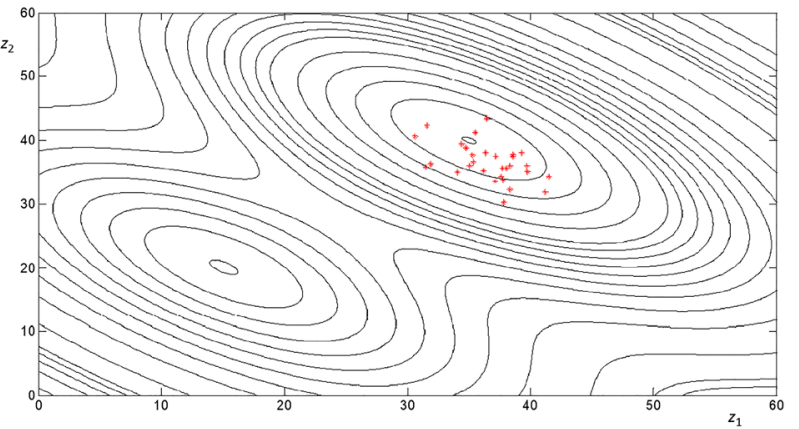

Fig. 15 Sequence of innovation for run 1 (Tolerance $=5,0)$, for selected periods 
Fisher was right writing that: "The rate of increase in the average fitness of a population is equal to the genetic variance of fitness of that population" (Fisher 1941); however, we think that it is possible to generalize this observation. Speeding up economic growth due to greater variety is observed not only in a case of evolutionary process approaching the equilibrium but also due to higher variety caused by the tolerant environment in the long run, thanks to more frequent emergence of radical and gradual innovations. Those radical innovations allow to explore new adaptive peaks and for the emergence of new equilibria, toward whom the process is continuously approaching.

\section{Compliance with ethical standards}

Conflict of interest The authors declare that they have no conflict of interest.

Open Access This article is licensed under a Creative Commons Attribution 4.0 International License, which permits use, sharing, adaptation, distribution and reproduction in any medium or format, as long as you give appropriate credit to the original author(s) and the source, provide a link to the Creative Commons licence, and indicate if changes were made. The images or other third party material in this article are included in the article's Creative Commons licence, unless indicated otherwise in a credit line to the material. If material is not included in the article's Creative Commons licence and your intended use is not permitted by statutory regulation or exceeds the permitted use, you will need to obtain permission directly from the copyright holder. To view a copy of this licence, visit http://creativecommons.org/licenses/by/4.0/.

\section{References}

Cipolla CM (1972) The diffusion of innovation in early modern Europe. Comp Stud Soc Hist 14:46-52

Cipolla CM (1993) Before the Industrial Revolution European Society and Economy 1000-1700. Routledge, London

Corneo G, Jeanne O (2009) A theory of tolerance. J Public Econ 93(5-6):691-702

Fisher RA (1930) The Genetical theory of natural selection. Oxford University Press, Oxford

Fisher RA (1941) The asymptotic approach to Behrens's integral, with further tables for the test of significance. Ann Eugenics 11:141-172

How Vienna produced ideas that shaped the West, The Economist, Dec 24th 2016 (http://www.economist. com/news/christmas-specials/21712044-city-century-how-vienna-produced-ideas-shaped-west)

Kwasnicka H, Kwasnicki W (1986) Diversity and development: tempo and mode of evolutionary processes. Technol Forecast Soc Change 30:223-243

Kwasnicki W (1996) Knowledge, innovation, and economy. An evolutionary exploration, 1st edn. Edward Elgar Publishing Ltd., Oficyna Wydawnicza Politechniki Wroclawskiej, Wroclaw Available for reading at Google Books: https://books.google.pl/books?id=di81JFzNTk0C\&printsec=frontcover\&source=gbs_ navlinks_s\&hl=pl\#v=onepage \&q\&f=false)

Kwasnicki W, Kwasnicka H (1992) Market, innovation, competition. An evolutionary model of industrial dynamics. J Econ Behav Organ 19:343-368

Metcalfe JS (1994) Competition, fisher's principle and increasing returns to selection. J Evol Econ 4:327-346

Mises, Ludvig von, 1996/1949, Human action. A treatise on economics 4th revised edition, San Francisco: Fox \&Wilkes

Mokyr J (1990) The lever of riches: technological creativity and economic progress. Oxford University Press, Oxford

Mokyr J (2016) A culture of growth the origins of the modern economy. Princeton University Press, Princeton

Nelson RR, Winter SG (1982) An evolutionary theory of economic change. Harvard University Press, Cambridge

Page SE (2007) The difference: how the power of diversity creates better groups, firms, schools, and societies. Princeton University Press, Princeton 
Page SE (2017) The diversity Bonus how great teams pay off in the knowledge economy. Princeton University Press, Princeton

Saviotti P (1996) Technological evolution, variety, and the economy. Edward Elgar, Aldershot and Lyme, NH, France

Schilling MA (2018) Quirky: the remarkable story of the traits, foibles, and genius of breakthrough innovators who changed the world. PublicAffairs, Hachette Book Group, New York

Schumpeter JA (2006) Capitalism, Socialism and Democracy. Rutledge, London (originally published in 1942).

Sidney W (1984) Schumpeterian competition in alternative technological regimes. J Econ Behav Organ 5: 287-320

Simon HA (1986) On behavioral and rational foundations of economic dynamics. In: Day RH, Eliasson G (eds) (1986), The Dynamics of Market Economies. North-Holland, Amsterdam

Publisher's note Springer Nature remains neutral with regard to jurisdictional claims in published maps and institutional affiliations. 